Article

\title{
Significant Reduction in Energy Consumption and Carbon Emission While Improving Productivity in Laser Drilling of CFRP Sheets with a Novel Stepped Process Parameter Parallel Ring Method
}

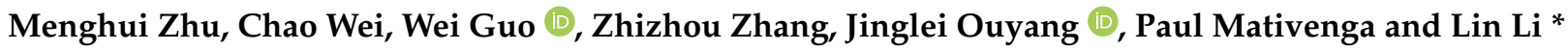

Citation: Zhu, M.; Wei, C.; Guo, W.; Zhang, Z.; Ouyang, J.; Mativenga, P.; Li, L. Significant Reduction in Energy Consumption and Carbon Emission While Improving Productivity in Laser Drilling of CFRP Sheets with a Novel Stepped Process Parameter Parallel Ring Method. J. Manuf.

Mater. Process. 2022, 6, 7 .

https://doi.org/10.3390/ jmmp6010007

Academic Editor: Steven Y. Liang

Received: 25 November 2021

Accepted: 28 December 2021

Published: 5 January 2022

Publisher's Note: MDPI stays neutral with regard to jurisdictional claims in published maps and institutional affiliations.

Copyright: (C) 2022 by the authors. Licensee MDPI, Basel, Switzerland. This article is an open access article distributed under the terms and conditions of the Creative Commons Attribution (CC BY) license (https:// creativecommons.org/licenses/by/ $4.0 /)$.

\author{
Laser Processing Research Centre, Department of Mechanical, Aerospace and Civil Engineering, \\ School of Engineering, The University of Manchester, Oxford Road, Manchester M13 9PL, UK; \\ menghui.zhu@manchester.ac.uk (M.Z.); chao.wei@manchester.ac.uk (C.W.); wei.guo@manchester.ac.uk (W.G.); \\ zhizhou.zhang@manchester.ac.uk (Z.Z.); jinglei.ouyang@manchester.ac.uk (J.O.); \\ p.mativenga@manchester.ac.uk (P.M.) \\ * Correspondence: lin.li@manchester.ac.uk
}

\begin{abstract}
Although laser drilling of carbon fibre-reinforced polymer (CFRP) composites offers the advantages of zero tool-wear and avoidance of fibre delamination compared with mechanical drilling, it consumes considerably more energy during the drilling process. This research shows that by using a new, stepped parameter parallel ring laser hole drilling method, an energy saving of $78.10 \%$ and an $18.37 \mathrm{gCO}_{2}$ reduction for each hole, while improving productivity by more than $300 \%$, can be achieved in laser drilling of $6 \mathrm{~mm}$ diameter holes in CFRP sheets of $2 \mathrm{~mm}$ in thickness, compared with previous laser drilling methods under the same drilling quality. The key reason for this is an increase in energy input to the inner rings enabling more rapid removal of the material, while the lower energy input for the outer ring provides a shielding trench to reduce the heat loss into the parent material. The results are compared with single-ring laser drilling and multiple-ring laser drilling with constant processing parameters, and a discussion is given on comparing with mechanical drilling and future prospects, including a combined mechanical drilling and laser pre-scribing process.
\end{abstract}

Keywords: CFRP; laser; drilling; energy efficiency; carbon emission; sustainable

\section{Introduction}

Carbon fibre-reinforced polymer (CFRP) has gained wide acceptance in different engineering applications including aircrafts, automobiles and consumer goods, due to its light weight and good strength [1,2]. CFRP is a class of polymer matrix composite (PMC) consisting of two distinct constituents-carbon fibre and polymer matrix [3,4]. Due to the presence of the carbon fibres, CFRPs show anisotropy. Hence, its tensile modulus, electrical and thermal conductivities are greater along the fibre direction than those perpendicular to the fibre axis [5]. Polymer matrix material acts as a binder that is able to bind the fibres together and protects the fibre from environmental damage [6]. Although CFRP products are usually cured into desired shapes, they often require hole drilling for assembly and fastening [7]. Drilling CFRP is different from drilling metals in many aspects [6]. Traditional mechanical drilling of CFRP suffers from various types of damage, including delamination, matrix cracks, burrs, thermal damage, etc. [6,8]. This can result in a high rejection rate of components [9]. Standard tungsten carbide coated drilling tools may only last 20 holes in CFRP dry drilling processes [10]. In the United States alone, the total tooling cost to produce holes in CFRP was estimated to be over 300 million dollars per year [11]. Therefore, if the tool life can be extended, not only can significant savings be gained in the hole production process in CFRP, but also considerable energy could be saved and $\mathrm{CO}_{2}$ emissions reduced. Recent research has proposed methods for reducing drilling defects [12-17]. However, high 
quality and high efficiency drilling of CFRP is hampered by excessive tool wear due to the abrasive nature of the carbon fibre [18].

Nonconventional drilling processes include abrasive waterjet (AWJ), laser, and electrical discharge machining (EDM). AWJ technology is able to cut a wide range of advanced materials including CFRP. However, the AWJ drilling process requires a high-pressure water jet, which may result in delamination, fibre pull-out, moisture absorption and particle embedment on drilled CFRP workpieces [6,18,19]. More importantly, the jet diameter in AWJ process is usually in a range of $0.5-2.5 \mathrm{~mm}$. Hence, this process may not be suitable to producing small features [20]. EDM utilizes spark discharge between electrode and workpiece to remove undesired material via melting and vaporization [21]. Low machining efficiency and high tool (electrode) wear limit the application of EDM for cutting or drilling CFRP [22].

Laser drilling is free of tool wear, has a higher degree of flexibility, and is noncontact $[18,20]$. However, challenges still exist in laser drilling of CFRP. The main challenge is to minimise the heat affected zone (HAZ), taper control and obtain high drilling efficiency. Laser drilling of CFRP composite has been investigated extensively in the last 30 years [7,23-29]. Infrared wavelength continuous wave or short pulse (e.g., nanosecond pulses, or micro-second pulses) laser drilling of CFRP is dominated by a photon-thermal process to disintegrate or vaporise the resin and carbon fibre. This process often causes thermal damage such as heat affect zone (HAZ), which is considered as a main obstacle in laser drilling/machining of CFRP [6]. The presence of HAZ is mainly due to the huge difference in thermal properties between carbon fibre and the polymer matrix [25]. More importantly, epoxy resin, as a matrix material in CFRP, shows low absorbability at the wavelength of about $1 \mu \mathrm{m}$ for high power fibre lasers. During the laser-workpiece interaction period, epoxy resin is degraded more quickly than the carbon fibre under the same amount of laser energy. However, carbon fibre has a good thermal conductivity. As a result, a great amount of thermal energy is conducted along the fibre direction to the surrounding resin, overheating/degradation and fibre debonding [22,30,31]. The size of HAZ is mainly described by the length of extruding fibre and defined by the zone where matrix material loses or reduces its ability to transfer load. It has been suggested that the extension of HAZ reaches a certain limit when fibre temperature is equal to the resin decomposition temperature [6,32]. Li et al. [23] used a diode-pumped solid state ultraviolet (UV) laser with nanosecond pulses to drill CFRP. They introduced a novel drilling method by utilizing multiple parallel rings to improve material removal rate. A minimum HAZ size of $50 \mu \mathrm{m}$ was achieved. Salama et al. [25] used a high power picosecond laser to drill a CFRP sheet of $6 \mathrm{~mm}$ in thickness with multiple-ring drilling strategy. A minimum HAZ of $25 \mu \mathrm{m}$ at the entrance side was reported. They suggested the use of lower laser power and higher scanning speed to reduce the extension of HAZ, due to less material-beam interaction time. Salama et al. [24] also stated that this parallel ring method would increase heat accumulation between each ring. However, the temperature may not be high enough to vaporise the carbon fibre. Instead, epoxy resin would be degraded and lose its ability to hold the fibre. Thus, chopped fibre chips can escape from the machining area. More importantly, the kerf width would be widened due to multiple rings or parallel lines which allow the debris and vapour to be ejected from the machining area more easily. Hence, machining efficiency was increased compared with single-ring drilling.

Li et al. [33] compared the drilling with single and multi-ring drilling strategy by using a high power fibre laser. They found that the machining time was significantly reduced by using multiple rings, multi-passes strategy compared with that of single-ring drilling. Li et al. [18] drilled CFRP with a fibre laser with adjustable pulse duration. Parallel ring drilling strategy was also adopted in their experiment. They found that a shorter pulse duration would reduce the size of HAZ due to less laser beam interaction time. A longer pulse duration would lead to carbonization which is due to matrix material being affected by heat. Thus, a shorter pulse duration was suggested. Apart from HAZ, hole wall tapering is another feature associated with laser drilling/machining of CFRP. Due to Gaussian 
distribution of the laser beam and the use of a round shaped beam, the laser energy is mostly concentrated on the centre, and decreases towards the beam edge. Additionally, as the material ejection from the top entry erodes the side walls, a tapered hole is often formed [6,34].

Climate change, global warming, and ozone depletion have drawn wide attention to investigating more energy efficient manufacturing processes [35]. Hence, it is crucial to investigate energy efficiency in manufacturing processes to achieve low carbon production and effective use of energy [36].

Despite a large amount of research in drilling CFRP composites, few studies have been conducted previously to investigate the effect of drilling process on energy consumption and $\mathrm{CO}_{2}$ emission.

In this investigation, a new approach of stepped laser pulse parameter multiplering drilling of CFRP is introduced (i.e., laser pulse parameters are different for different rings) and the energy consumption, carbon emission, drilling time, and hole quality are evaluated. The key novelty of the research is the development and characterization of a new drilling method that has shown significant reduction in energy consumption and significant improvement in drilling efficiency compared with the previously reported laser drilling with parallel rings under constant drilling parameters and it is the first study of its kind in laser drilling of CFRP.

\section{Materials and Methods}

\subsection{Workpiece Material}

Double-sided high strength CFRP sheets of $2 \mathrm{~mm}$ thickness were supplied by Easy Composite Ltd., as shown in Figure 1 . The woven fibre directions were in $0^{\circ} / 90^{\circ}$. Each cured CFRP sheet consisted of 3 layers of XPREG XC $130210 \mathrm{~g}$ and 3 layers of XPREG XC $130450 \mathrm{~g}$ which was cured at $80-120{ }^{\circ} \mathrm{C}$ temperature. Its density is $1470.05 \mathrm{~kg} / \mathrm{m}^{3}$ [37].

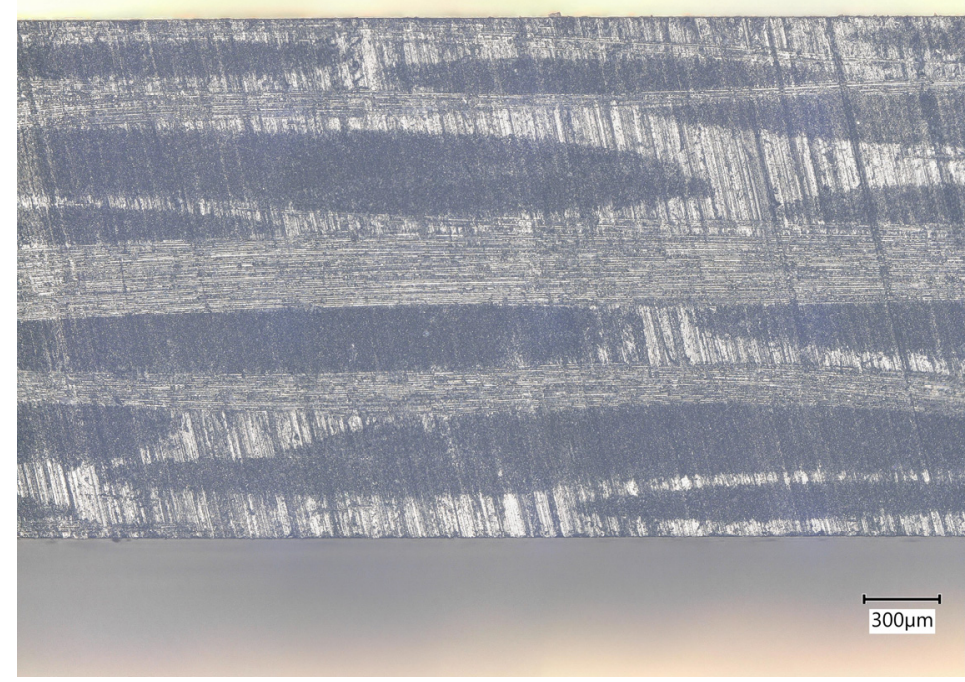

Figure 1. An optical microscopic image of a CFRP sheet of $2 \mathrm{~mm}$ in thickness supplied by Easy Composite Ltd.

Each sample was machined into $20 \mathrm{~mm}$ by $20 \mathrm{~mm}$ square pieces. The cross-section of laser drilled workpieces were prepared by cutting with a diamond saw cutter. Optical microscopic images were taken via a digital microscope (VHX-5000, Keyence, Milton Keynes, UK). Scanning electron microscopy was carried out to study the internal hole wall surface morphology and fibre behaviour. 


\subsection{Stepped Laser Parameter Multiple Rings with Multiple Pass Drilling Strategy}

In previous studies [24,33], it was found that the lower part CFRP hole was difficult to be removed by the laser beam with the conventional single-ring drilling strategy. $\mathrm{Li}$ et al. [23] pioneered laser drilling/machining of CFRP with multiple rings with multiple passes. The study showed that multiple rings were able to enlarge the machining area (or slot), which allowed debris and vapour to be ejected from the drilling zone more easily. Hence, the laser could machine deeper. In 2020, Li et al. [33] also reported that multiple-ring drilling strategy is able to significantly reduce machining time comparing with that using a single-ring approach. In these previous studies, the same laser processing parameters were used for all the rings.

In order to further improve laser drilling of CFRP energy efficiency, a new stepped laser parameter multiple-ring drilling strategy was introduced in this research. The drilling toolpaths are illustrated in Figure 2. Figure 2a shows the scheme for the single-ring drilling while the multi-ring drilling is shown in Figure 2b. In Figure 2b, the laser beam started drilling from the outer ring to the inner ring. Each ring was scanned once from starting point to end point. Then, the next series of scans took place until the hole was drilled through. Laser parameters for each ring are listed in Tables 1-3. The effects of two different multiple-ring drilling strategies (with stepped parameters and with constant parameters) and single-ring drilling strategy were compared. The reason to choose these laser parameters are discussed in Section 3.1. Each experiment was repeated 5 times to obtain the average values of thermal damage on drilled CFRP workpiece and for the energy efficiency evaluation.

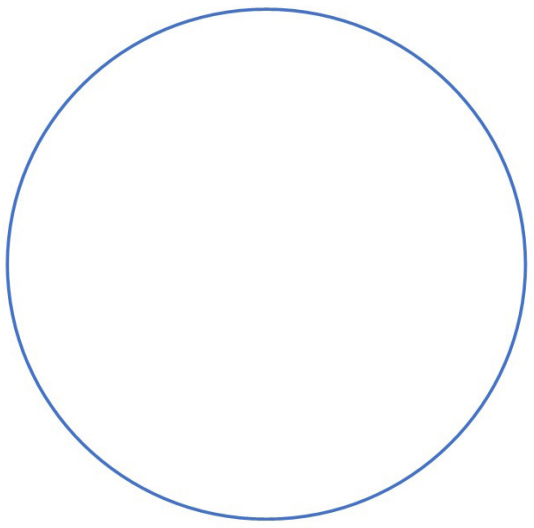

(a)

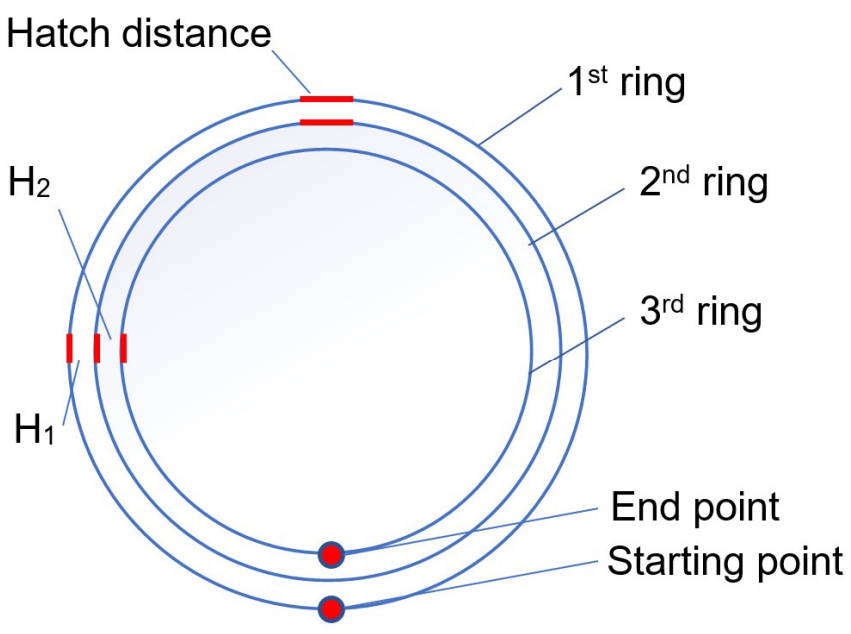

(b)

Figure 2. Schematic diagram of different laser drilling methods: (a) single ring; (b) multiple rings.

Table 1. Laser processing parameters for the stepped laser parameter multiple-ring drilling method.

\begin{tabular}{|c|c|c|c|c|c|c|c|c|}
\hline \multicolumn{9}{|c|}{ Stepped Laser Parameter Multiple-Ring Drilling Method } \\
\hline Sample No. & & 1st Ring & 2nd Ring & 3rd Ring & Feed Rate & Laser Spot Size & Hatch Distance & Hole Diameter \\
\hline \multirow{2}{*}{ S1 } & Laser power & $150 \mathrm{~W}$ & $200 \mathrm{~W}$ & $200 \mathrm{~W}$ & \multirow{8}{*}{$70 \mathrm{~mm} / \mathrm{s}$} & \multirow{8}{*}{$130 \mu \mathrm{m}$} & \multirow{8}{*}{$\mathrm{H}_{1}=\mathrm{H}_{2}=100 \mu \mathrm{m}$} & \multirow{8}{*}{$6 \mathrm{~mm}$} \\
\hline & Pulse frequency & $100 \mathrm{~Hz}$ & $200 \mathrm{~Hz}$ & $200 \mathrm{~Hz}$ & & & & \\
\hline \multirow{2}{*}{ S2 } & Laser power & $150 \mathrm{~W}$ & $300 \mathrm{~W}$ & $300 \mathrm{~W}$ & & & & \\
\hline & Pulse frequency & $100 \mathrm{~Hz}$ & $200 \mathrm{~Hz}$ & $200 \mathrm{~Hz}$ & & & & \\
\hline \multirow{2}{*}{ S3 } & Laser power & $150 \mathrm{~W}$ & $400 \mathrm{~W}$ & $400 \mathrm{~W}$ & & & & \\
\hline & Pulse frequency & $100 \mathrm{~Hz}$ & $200 \mathrm{~Hz}$ & $200 \mathrm{~Hz}$ & & & & \\
\hline \multirow{2}{*}{ S4 } & Laser power & $150 \mathrm{~W}$ & $500 \mathrm{~W}$ & $500 \mathrm{~W}$ & & & & \\
\hline & Pulse frequency & $100 \mathrm{~Hz}$ & $200 \mathrm{~Hz}$ & $200 \mathrm{~Hz}$ & & & & \\
\hline
\end{tabular}


Table 2. Laser processing parameters for the constant laser parameter multiple-ring drilling method.

\begin{tabular}{|c|c|c|c|c|c|c|c|c|}
\hline \multicolumn{9}{|c|}{ Constant Laser Parameter Multiple Ring Drilling Method } \\
\hline Sample No. & & 1st Ring & 2nd Ring & 3rd Ring & Feed Rate & Laser Spot Size & Hatch Distance & Hole Diameter \\
\hline \multirow{2}{*}{ S5 } & Laser power & $200 \mathrm{~W}$ & $200 \mathrm{~W}$ & $200 \mathrm{~W}$ & & & & \\
\hline & Pulse frequency & $100 \mathrm{~Hz}$ & $100 \mathrm{~Hz}$ & $100 \mathrm{~Hz}$ & & & & \\
\hline \multirow{2}{*}{ S6 } & Laser power & $300 \mathrm{~W}$ & $300 \mathrm{~W}$ & $300 \mathrm{~W}$ & & & & \\
\hline & Pulse frequency & $100 \mathrm{~Hz}$ & $100 \mathrm{~Hz}$ & $100 \mathrm{~Hz}$ & $70 \mathrm{~mm} / \mathrm{s}$ & $130 \mu \mathrm{m}$ & $\mathrm{H}_{1}=\mathrm{H}_{2}=100 \mu \mathrm{m}$ & $6 \mathrm{~mm}$ \\
\hline \multirow{2}{*}{ S7 } & Laser power & $400 \mathrm{~W}$ & $400 \mathrm{~W}$ & $400 \mathrm{~W}$ & & & & \\
\hline & Pulse frequency & $100 \mathrm{~Hz}$ & $100 \mathrm{~Hz}$ & $100 \mathrm{~Hz}$ & & & & \\
\hline \multirow{2}{*}{ S8 } & Laser power & $500 \mathrm{~W}$ & $500 \mathrm{~W}$ & $500 \mathrm{~W}$ & & & & \\
\hline & Pulse frequency & $100 \mathrm{~Hz}$ & $100 \mathrm{~Hz}$ & $100 \mathrm{~Hz}$ & & & & \\
\hline
\end{tabular}

Table 3. Laser processing parameters for the single-ring drilling method.

\begin{tabular}{|c|c|c|c|c|c|c|}
\hline \multicolumn{7}{|c|}{ Single Ring Drilling Method } \\
\hline Sample No. & & 1st Ring & Feed Rate & Laser Spot Size & Hatch Distance & Hole Diameter \\
\hline \multirow{2}{*}{ S9 } & Laser power & $300 \mathrm{~W}$ & \multirow{6}{*}{$70 \mathrm{~mm} / \mathrm{s}$} & \multirow{6}{*}{$130 \mu \mathrm{m}$} & \multirow{6}{*}{$\mathrm{H}_{1}=\mathrm{H}_{2}=0 \mu \mathrm{m}$} & \multirow{6}{*}{$6 \mathrm{~mm}$} \\
\hline & Pulse frequency & $100 \mathrm{~Hz}$ & & & & \\
\hline \multirow{2}{*}{ S10 } & Laser power & $400 \mathrm{~W}$ & & & & \\
\hline & Pulse frequency & $100 \mathrm{~Hz}$ & & & & \\
\hline \multirow{2}{*}{ S11 } & Laser power & $500 \mathrm{~W}$ & & & & \\
\hline & Pulse frequency & $100 \mathrm{~Hz}$ & & & & \\
\hline
\end{tabular}

\subsection{Laser Processing System and Carbon Emission Estimation Method}

The laser system used for drilling was an ytterbium single-mode fibre laser (YLP-500WC, IPG) at a wavelength of $1070 \mathrm{~nm}$ and a maximum power of $500 \mathrm{~W}$. It can work in either modulated pulsed mode or continuous wave $(\mathrm{CW})$ mode. The focal position was $1 \mathrm{~mm}$ above the top surface of workpiece. A water chiller (CR8U20-CC, Thermal Exchange) was used to cool down the laser system. Argon gas was used as the shielding gas. All operation was controlled remotely via Mach $3 \mathrm{CNC}$ software. Machining time was measured via Mach 3 software. A Fluke 434 power/energy analyser was used to measure the energy consumption for each processing equipment, including the laser system, the water chiller unit, the controlling computer, the function generator and the CNC control system during the drilling process.

The carbon emission of laser drilling process was calculated via the following equation $[36,38]$ :

$$
C_{\text {part }}=E_{\text {part }} \times C_{E S}
$$

where $C_{\text {part }}\left(\mathrm{gCO}_{2}\right)$ stands for the carbon emission of total electricity used. $E_{\text {part }}(\mathrm{J})$ is the total energy consumed during the machining process. $C_{E S}\left(\mathrm{gCO}_{2} / \mathrm{J}\right)$ is the carbon emission signature which is calculated from the energy mix that supplies electrical power.

The specific energy required for removing $1 \mathrm{~kg}$ material can be evaluated from:

$$
E_{\text {Specific }}=\frac{E_{\text {part }}}{M_{\text {removal }}}
$$

where $E_{\text {specific }}(\mathrm{J} / \mathrm{kg})$ is the specific energy required for removing $1 \mathrm{~kg}$ material. $E_{\text {part }}(\mathrm{J})$ is the total energy cost during the machining process. $M_{\text {removal }}(\mathrm{kg})$ is the mass of the total material removed by the laser.

\subsection{Bearing Strength Test of Laser Drilled CFRP Workpieces}

This test was designed to compare the bearing strengths of laser drilled CFRP workpiece via stepped laser parameter multiple-ring drilling method and constant laser parameter multiple-ring drilling method as well as mechanical hole drilling method. An INSTRON 
4507 tensile machine was used for the bearing test. The design of the test was based on ASTM D5961 standard, Procedure-A, "double shearing with single-pin fastener" [39]. The specification of the parameters is listed in Table 4, which is in compliance with ASTM D5961 standard. The test was run at a constant displacement rate of $1 \mathrm{~mm} / \mathrm{min}$. The drawing of specimen and pin-load setup is shown in Figure 3. Bearing strength tests were conducted for S3 and S5 samples. Holes drilled via mechanical dry drilling process was also compared with laser drilled holes. The specifications of drilling tool and drilling parameters are listed in Table 5. A piece of wood was placed underneath the CFRP workpiece during mechanical drilling to prevent serious delamination on the hole exit side. Each set of tests was repeated 3 times to obtain the average value of maximum load and displacement.

Table 4. Specification of actual dimensions on CFRP workpiece (SI).

\begin{tabular}{cc}
\hline Parameter & Actual Dimension (mm) \\
\hline Hole diameter, D & $6 \pm 0.02$ \\
Material thickness, h & $2 \pm 0.06$ \\
Length, L & $135 \pm 0.5$ \\
Width, w & $36 \pm 0.5$ \\
Edge distance, e & $18 \pm 0.4$ \\
Countersink & None \\
\hline
\end{tabular}
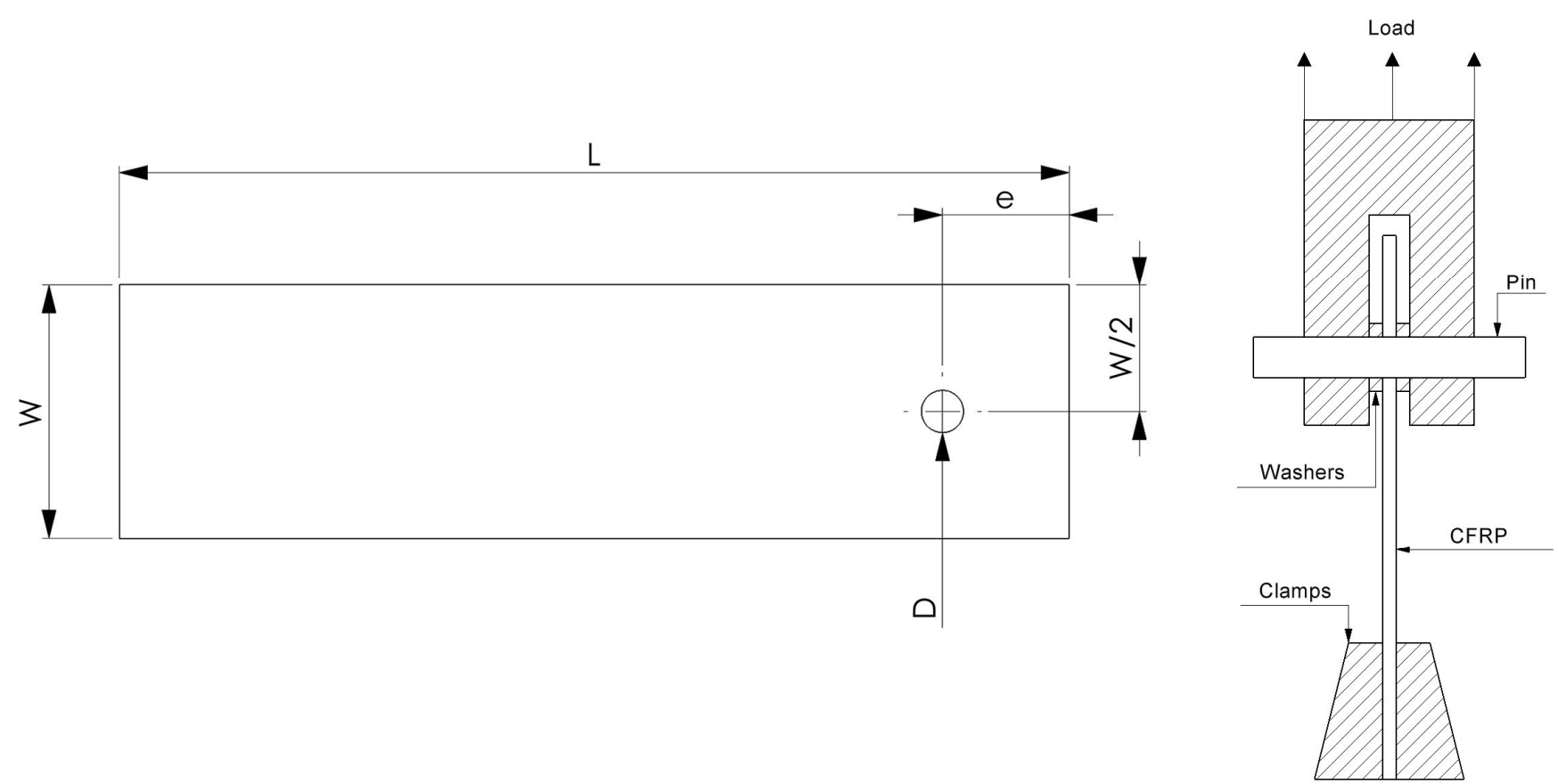

Figure 3. Schematic diagram of specimen and pin-load setup for the bearing strength test.

\subsection{Mechanical Finishing Process}

In order to reduce or eliminate the thermal damage on laser drilled CFRP workpiece, a mechanical finishing process was introduced. The drilling tool specifications and drilling parameters are illustrated in Table 5, which follow the specifications given by Cutwel Ltd. The mechanical drill was engaged reversely from the laser drilled hole exit side, as shown in Figure 4. 


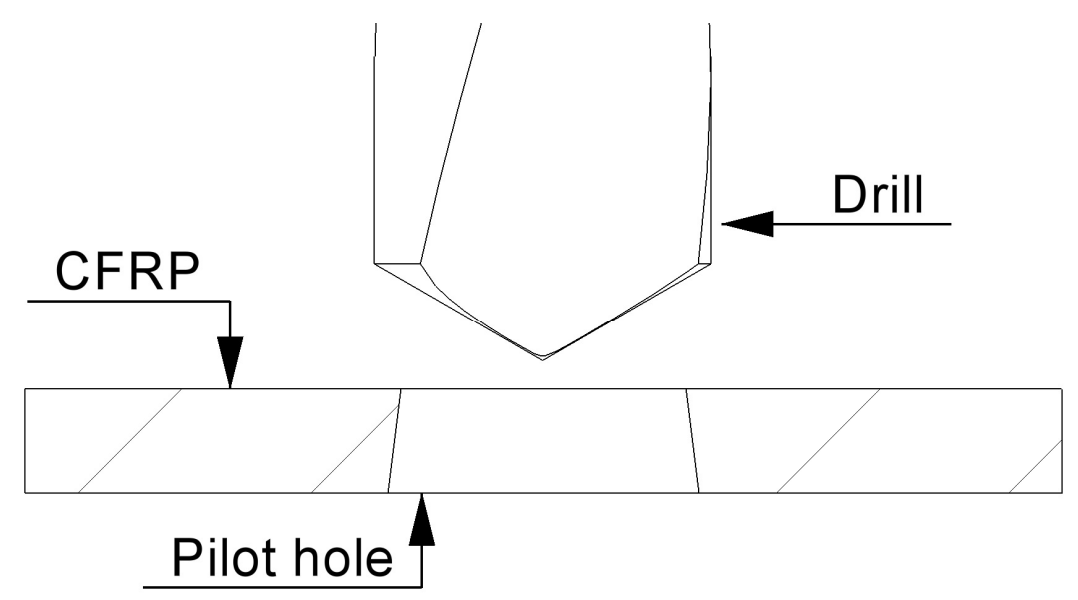

Figure 4. Schematic diagram of mechanical hole finishing process.

Twist drills have gained great interest in industrial applications due to its good drilling performance and relatively lower cost [40]. This mechanical finishing process was aimed to use low-cost drill bits to eliminate delamination without using a supporting material by combining with the laser drilling. Hence, this type of drill was the chosen for the mechanical finishing process.

Table 5. Specification of mechanical drilling tool and drilling parameters [41,42].

\begin{tabular}{cc}
\hline Parameter & Specification \\
\hline Tool substrate & Micro grain Solid Carbide \\
Surface Treatment & Uncoated \\
Point Angle & $118^{\circ}$ \\
Helix angle & $33^{\circ}$ \\
Diameter & $6 \mathrm{~mm} / 6.5 \mathrm{~mm}$ \\
Feed rate & $0.025 \mathrm{~mm} / \mathrm{rev}$ \\
Spindle speed & $2500 \mathrm{rpm}$ \\
\hline
\end{tabular}

\section{Results}

\subsection{Evaluation of Pulse Frequency Effect}

A stepped pulse frequency (i.e., repetition rate) method was chosen in the laser drilling of the CFRP sheet. Figure 5 shows a string of spots formed on stainless-steel surface for the stepped laser parameter multiple-ring drilling method.

During the laser drilling process in the stepped laser parameter multiple-ring drilling method, $100 \mathrm{~Hz}$ of pulse frequency was chosen for the first ring. The irradiated area is shown in Figure 5a. A pulse frequency of $200 \mathrm{~Hz}$ was used for the second and third rings to increase the material removal rate. The surface morphology and pulse separation are shown in Figure 5b. The effect of pulse overlaps via this stepped parameter multiple-ring method is shown in Figure $5 \mathrm{c}, \mathrm{d}$. When the laser beam interacts with a material, an area of HAZ will be induced around each laser interaction spot via heat conduction. If there is an air gap between each ring, the extension of HAZ will be stopped. As a result, the first ring $(100 \mathrm{~Hz})$ would act as a barrier to prevent further heat conduction into the outer material and the carbon fibre was cut, and resin was removed. As shown in Figure 6, the heat conduction to the outer material by the second and third rings would be blocked by the first ring. Ideally, the resultant HAZ left on workpiece is close to the one induced by first ring only. More importantly, the HAZ size was mainly determined by the effect of the first ring and the heat damage induced by inner rings could not propagate into the outer material beyond the first ring. As a result, the stepped laser parameter multiple-ring drilling method allowed for a higher material removal rate in the inner material than that of the parent material, due to the increased laser energy input in the second and third rings, 
as shown in Figure 7a. This would allow more energy to be used for the material removal, rather than being wasted by conduction through the carbon fibres to the outer material beyond the first ring. This is compared with parallel ring drilling pulse overlaps using constant laser processing parameters as shown in Figure $7 \mathrm{~b}$.

\subsection{Evaluation of Drilling Quality for Each Method}

Figure $8 \mathrm{a}, \mathrm{c}$ shows the degree of thermal damage in laser-drilled CFRP workpieces. S1-S4 were samples produced using the stepped laser parameter multiple-ring drilling method. The increased laser power and repetition rate resulted in an increase in the average thermal damage on the top surface, the cross-section, and the bottom surface. Meanwhile, the drilling time was reduced from $240 \mathrm{~s}$ to $28 \mathrm{~s}$, as shown in Figure $8 \mathrm{~b}$. The required total number of scans was also reduced from 267 to 30 passes. Since the first ring was used as a protection ring, when increasing the laser power from $200 \mathrm{~W}$ to $400 \mathrm{~W}$, the average heat-affected zone sizes on the top surface, cross-section and bottom surface were increased by $14.80 \%, 11.73 \%$ and $17.61 \%$, respectively. However, when the laser power increased to $500 \mathrm{~W}$, this protection barrier was finally exceeded, which resulted in greater thermal damage on the drilled CFRP workpiece. This result was useful for selecting suitable/optimal laser processing parameters in the stepped laser parameter multiple-ring drilling method. When evaluating the drilling quality, a $350 \mu \mathrm{m}$ HAZ size was set as the maximum limit. Hence, S4 was not chosen, due to an excessive size of HAZ. S3 resulted in $314 \mu \mathrm{m}$ of HAZ on the top surface, a $314 \mu \mathrm{m}$ cross-section HAZ and a $234 \mu \mathrm{m}$ bottom surface HAZ. The drilling time was 53 s, which was the quickest set among S1-S3. The required number of scans was 54 passes for $\mathrm{S} 4$.
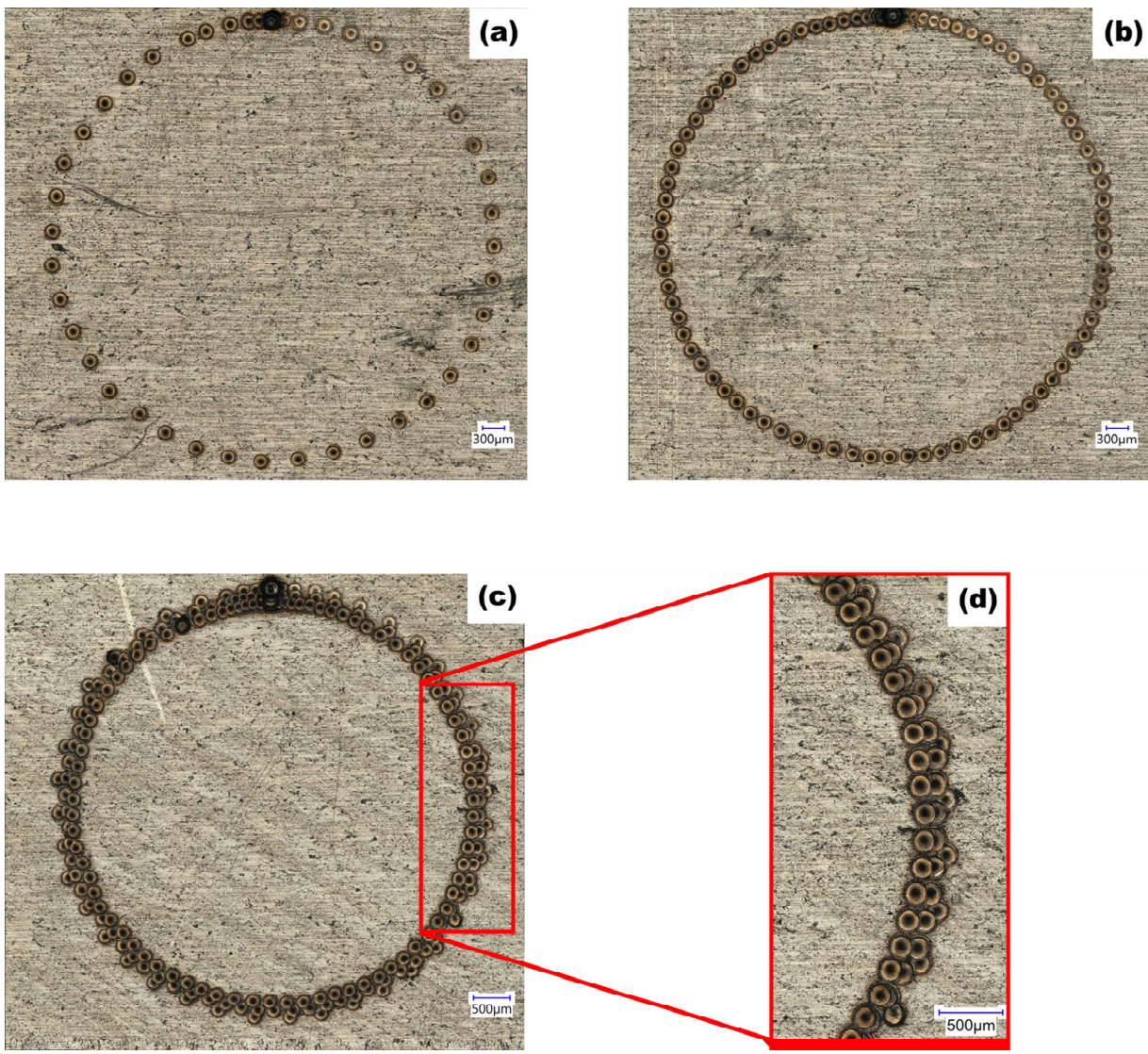

Figure 5. Pulse separation and overlaps with single-ring and multiple-ring drilling strategy: (a) $100 \mathrm{~Hz}$ pulse, single ring; (b) $200 \mathrm{~Hz}$ pulse, single ring. Three rings approach with $100 \mathrm{~Hz}$ and $200 \mathrm{~Hz}$ pulses: (c) $\mathrm{H}_{1}=\mathrm{H}_{2}=100 \mu \mathrm{m}$; (d) close up view of multiple-ring overlap at $100 \mathrm{~Hz}$ and $200 \mathrm{~Hz}$ pulses. 


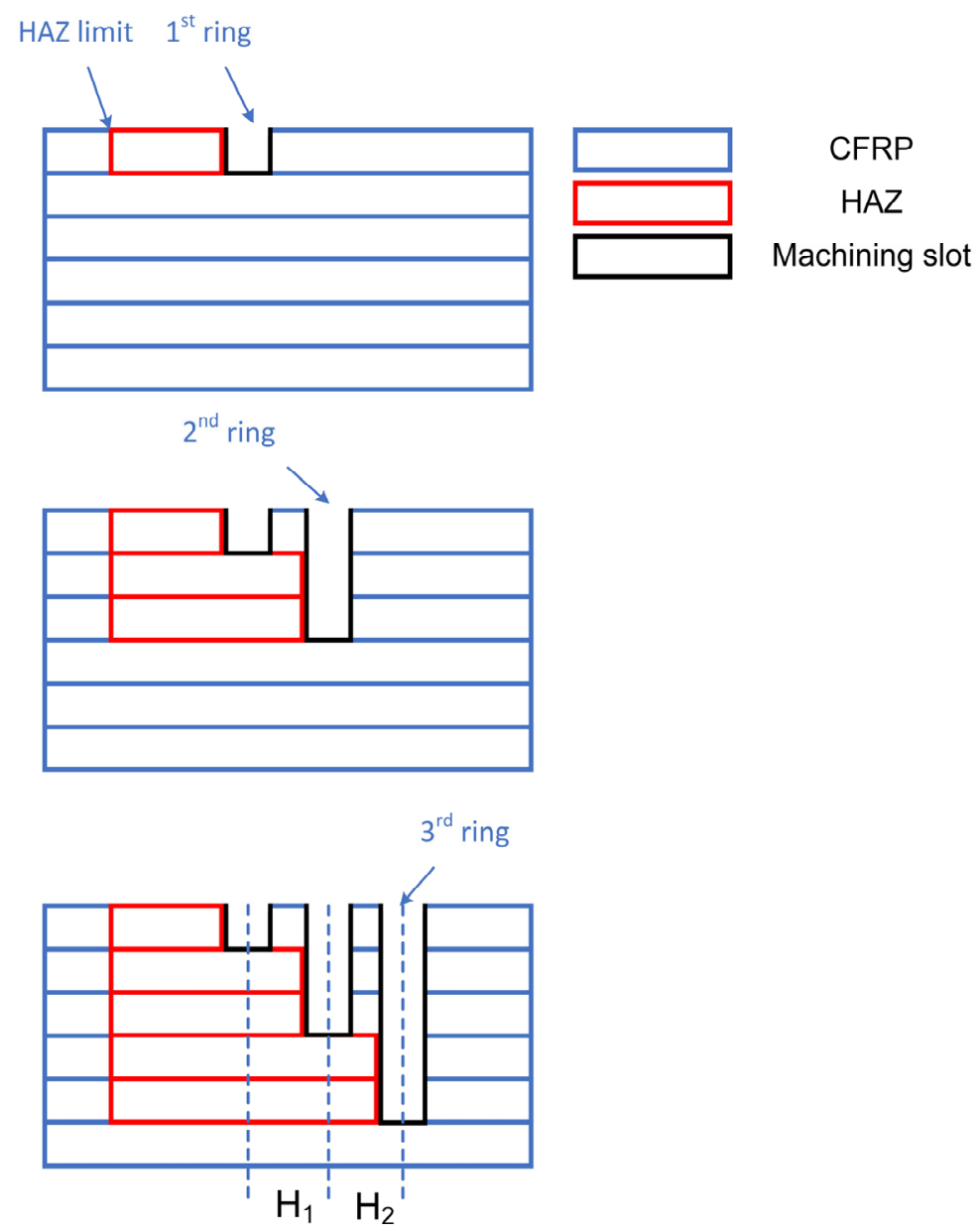

Figure 6. Schematic diagram of stepped laser parameter multiple-ring laser drilling process.

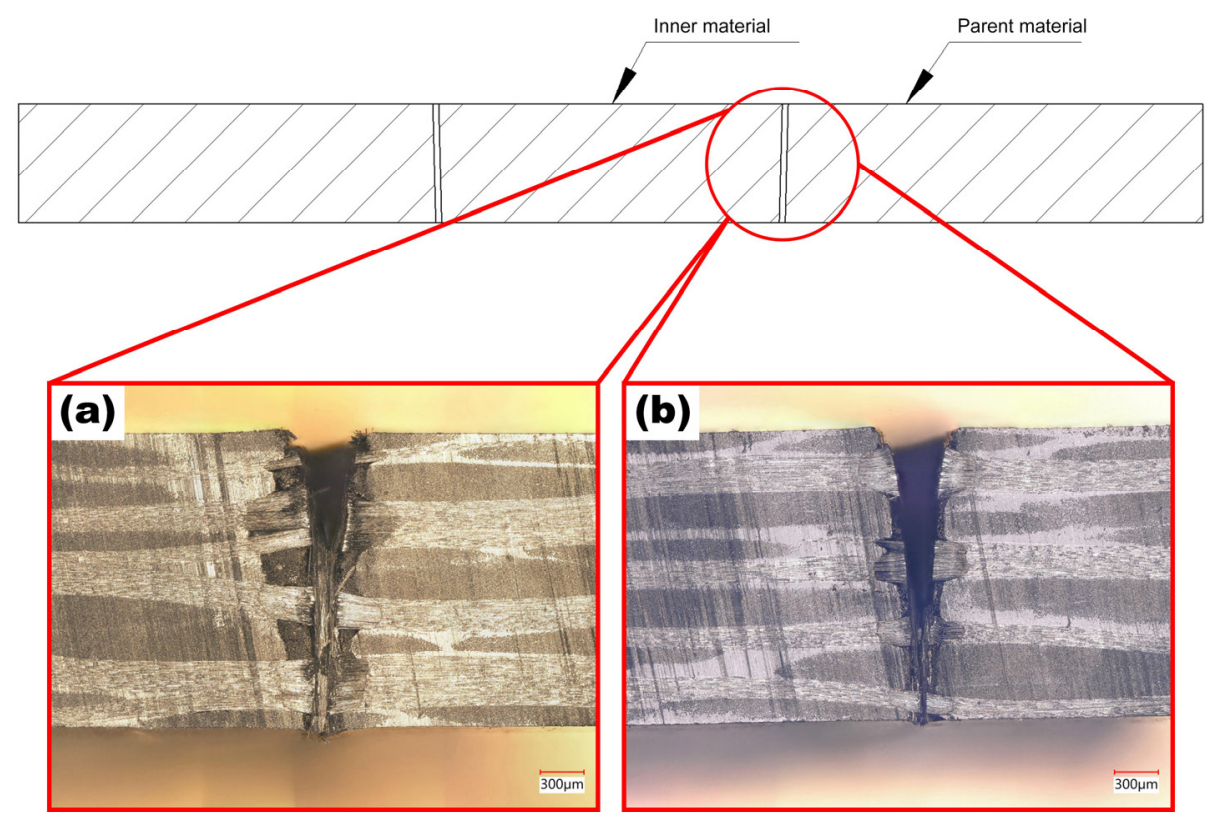

Figure 7. Comparison of cross sections for CFRP workpieces drilled via different methods: (a) stepped laser parameter multiple-ring drilling method; (b) constant laser parameter multiple-ring drilling method. 
(a)

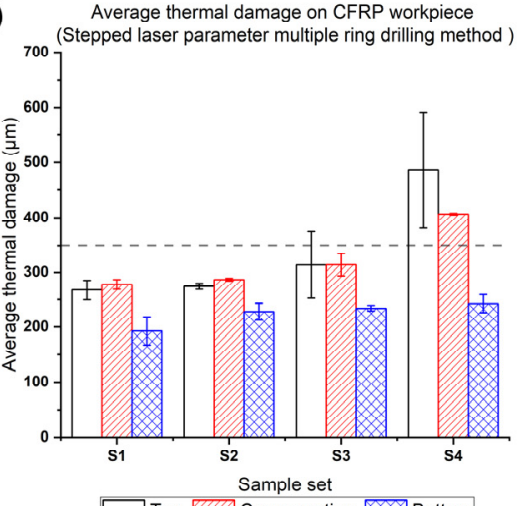

(c)

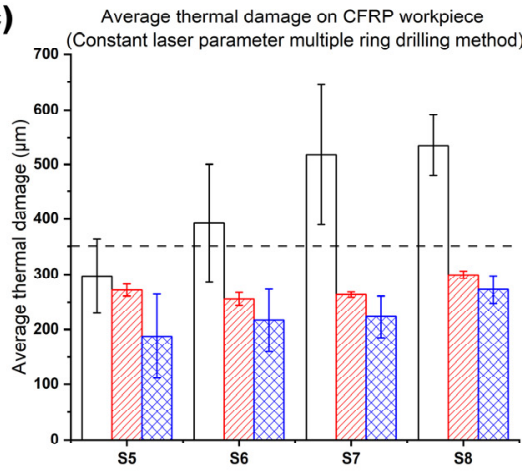

Sample set

(e)
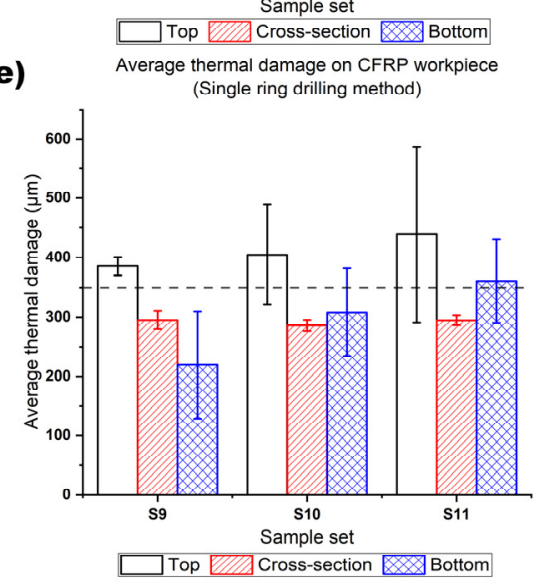

(b)

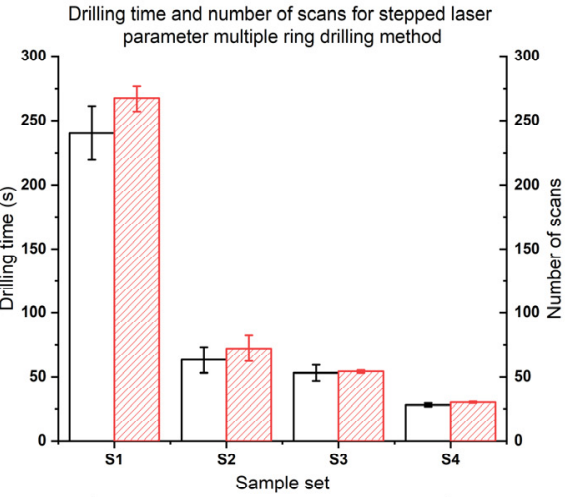

Drilling time Number of scans

(d)

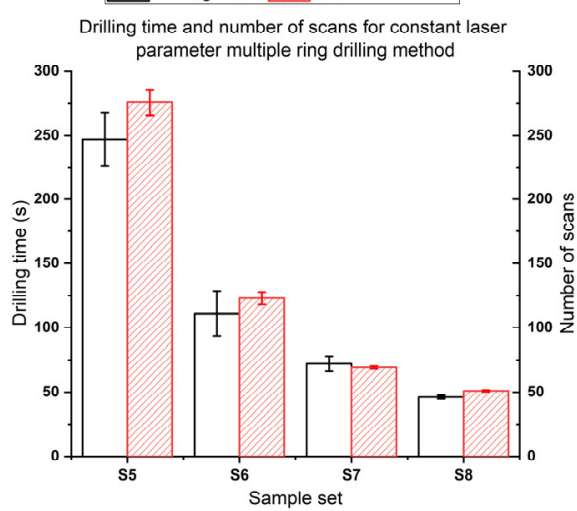

$\square$ Drilling time Number of scans

(f)

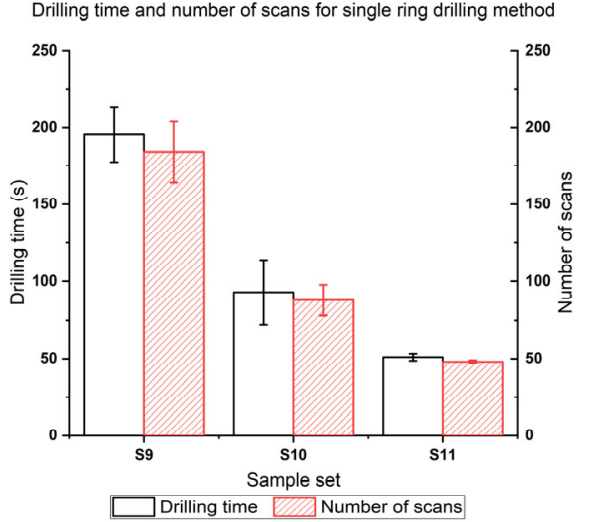

Figure 8. Comparison of average thermal damage via stepped laser parameter multiple-ring drilling method, constant laser parameter multiple-ring drilling method, and single-ring drilling method.

For samples S5-S8 produced with the constant laser parameter multiple-ring drilling method, an increase in laser power from $200 \mathrm{~W}$ to $500 \mathrm{~W}$ resulted in greater average HAZs than those with the stepped laser parameter multiple-ring drilling method on the top surface and cross-section from $297 \mu \mathrm{m}$ to $536 \mu \mathrm{m}$ and from $271 \mu \mathrm{m}$ to $299 \mu \mathrm{m}$, respectively, as shown in Figure 8c. When increasing the laser power from $200 \mathrm{~W}$ to $500 \mathrm{~W}$, the drilling time was reduced non-linearly, as shown in Figure $8 \mathrm{~d}$. According to the experimental result from S5 and S6, the drilling time was reduced from $247 \mathrm{~s}$ to $111 \mathrm{~s}$. The number of scans was reduced from 276 to 123 passes, which was higher than stepped laser parameter multiplering drilling method. However, S6 produced lower average cross-section HAZ than that of S5. This was due to increased laser and material interaction time in S5 which led to greater extension of HAZ. Therefore, it would be important to strike a balance between material removal rate and the extent of cross-section HAZ. Hence, increased laser power resulted larger HAZ on top surface. Although S6, S7 and S8 had lower average cross-section HAZs than that of S3, tremendous top surface HAZ lead to unacceptable drilling quality for S6, S7 
and S8. Therefore, the later sets were not selected according to the $350 \mu \mathrm{m} \mathrm{HAZ} \mathrm{limit.} \mathrm{The}$ best quality produced by the constant laser parameter multiple-ring drilling method was S5, which resulted in a $297 \mu \mathrm{m}$ average HAZ on the top surface, a $271 \mu \mathrm{m}$ average HAZ in the cross-section and a $188 \mu \mathrm{m}$ average HAZ on the bottom surface. The drilling time was $247 \mathrm{~s}$. The required number of scans was 276 passes.

When comparing between S3 and S5, the resultant average top surface HAZ via the stepped laser parameter multiple-ring drilling method and constant laser parameter multiple-ring drilling method was $314 \mu \mathrm{m}$ and $297 \mu \mathrm{m}$, respectively. The average cross section HAZ in stepped laser parameter multiple-ring drilling method was $314 \mu \mathrm{m}$. However, in the constant laser parameter multiple-ring drilling method, this value was $271 \mu \mathrm{m}$. Therefore, the resultant average maximum cross section HAZ by the stepped laser parameter multiple-ring drilling method was greater than that of constant laser parameter multiple-ring drilling method by $43 \mu \mathrm{m}$. On the bottom surface, the stepped laser parameter multiple-ring drilling method also produced a larger HAZ than that of the constant laser parameter multiple-ring drilling method, which was $234 \mu \mathrm{m}$ and $188 \mu \mathrm{m}$, respectively. This was due to increased material removal rate in the inner ring via the stepped process parameter method, which means the second and third rings were drilled more quickly than the first ring. As a result, the effect of protection from the first ring was limited on the bottom surface. In the stepped laser parameter multiple-ring drilling method, the first ring acted as a barrier, which helped prevent the extension of the HAZ, as shown in Figure 6. Therefore, with a relatively lower laser energy input for the first ring, the extension of the HAZ through the subsequent inner rings was limited. If the laser energy input was further increased, the protection from first ring would reach a certain limit and eventually resulted in greater thermal damage on CFRP workpiece.

Figure 8e shows the average thermal damage on CFRP workpiece via single-ring drilling method. For samples S9-S11, the laser power was increased from $300 \mathrm{~W}$ to $500 \mathrm{~W}$, the average thermal damage on top surface was increased from $386 \mu \mathrm{m}$ to $439 \mu \mathrm{m}$. On cross-sectional view, $300 \mathrm{~W}$ laser power (S9) resulted in a $295 \mu \mathrm{m}$ of average HAZ. If the laser power was increased to $400 \mathrm{~W}$ (S10), the average cross section HAZ was reduced to $286 \mu \mathrm{m}$. This phenomenal was mainly due to excessive laser/material interaction time in S9 (195 s) than S10 (93 s), as shown in Figure 8f. Thus, the HAZ would extend radially and axially, which would result in excessive HAZ on cross-section view. For sample S11, at $500 \mathrm{~W}$ laser power, the average cross-section HAZ was increased to $295 \mu \mathrm{m}$ due to further increased laser energy input. The drilling time was $51 \mathrm{~s}$. On drilled-hole exit, the average thermal damage was increased from $219 \mu \mathrm{m}$ to $361 \mu \mathrm{m}$ when increasing the laser power from $300 \mathrm{~W}$ to $500 \mathrm{~W}$. When the laser power was $200 \mathrm{~W}$, even for more than $20 \mathrm{~min}$, the hole could not be drilled using a single-ring drilling approach due to self-limiting effect.

Comparing S6-S8 and S9-S11, even the constant laser parameter multiple-ring drilling method showed much better drilling efficiency than the single-ring drilling method without further increasing thermal damage.

Figure 9 shows the comparison of hole diameter and taper angle when drilling with stepped laser parameter multiple-ring drilling method and constant laser parameter multiple-ring drilling method. According to the experimental data, no significant change in hole entry side diameter by utilizing different drilling methods. However, the diameter of the exit side hole was strongly affected by different drilling methods. For samples S1-S4, increased laser power $(200 \mathrm{~W}-500 \mathrm{~W})$ resulted increase in hole exit diameter. Thus, the taper angle was decreased from $5.99^{\circ}$ to $3.62^{\circ}$. For samples S5-S8, the laser power was also increased from $200 \mathrm{~W}$ to $500 \mathrm{~W}$, which resulted in decreased taper angle from $6.04^{\circ}$ to $4.40^{\circ}$. Therefore, increased laser energy input in drilling of CFRP would result in a reduction in taper angle [24]. The stepped laser parameter multiple-ring drilling method increased laser energy input in second and third rings; thus, the taper angle left on the workpiece was smaller than constant process method. 


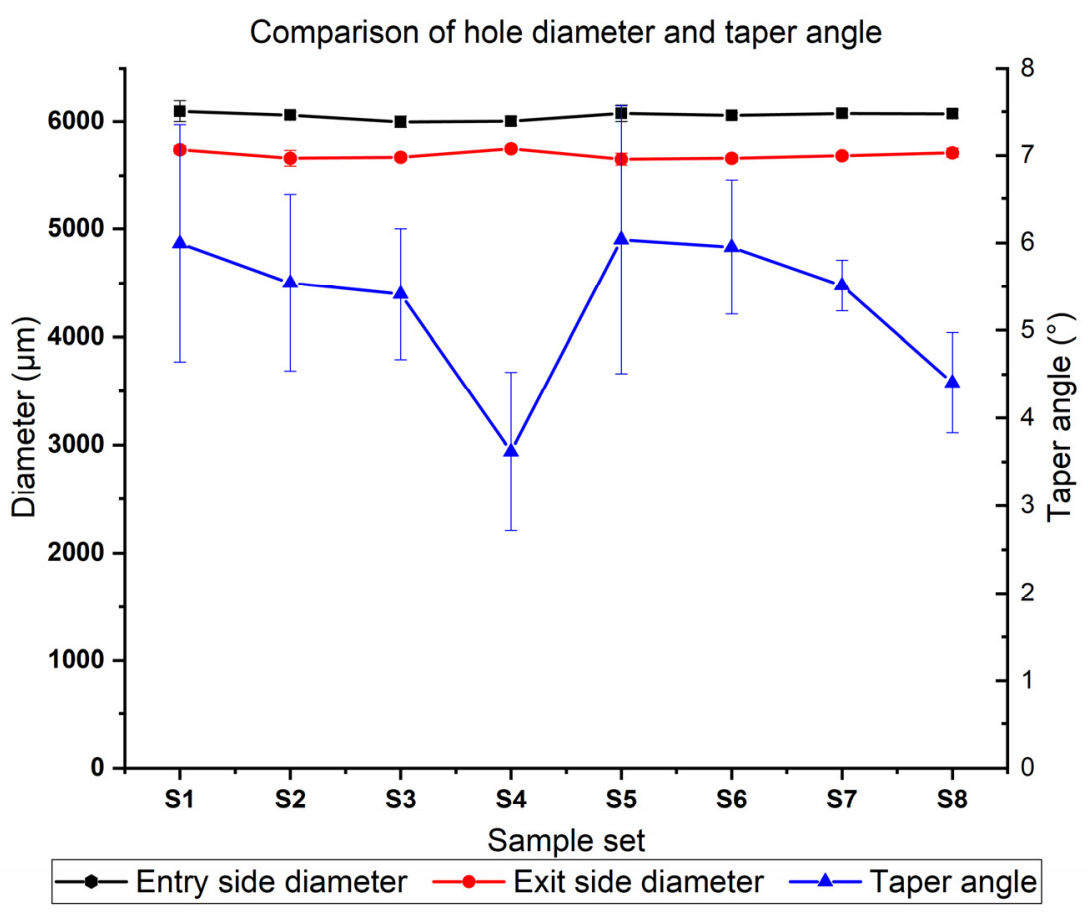

Figure 9. Comparison of hole diameter and taper angle via stepped laser parameter multiple-ring drilling method and constant laser parameter multiple-ring drilling method.

Figure 10 shows optical images of a CFRP workpieces after laser drilling with the two different parallel ring drilling methods. From the cross-sectional view, the HAZ was increased more rapidly along the fibre direction. However, by using the stepped laser parameter multiple-ring drilling method, more HAZ was detected in the direction that was perpendicular to the fibre direction. This is because in the stepped laser parameter multiple-ring drilling method, the laser energy input was not constant. The second and third rings produced more HAZ than the first ring. Therefore, the increased laser energy input also affected the area that was perpendicular to the fibre direction. Both top and bottom surfaces showed similar result, regardless of the difference in the HAZ. Resin spatter was formed on the top surface, which was due to the re-solidification of ejected resin from the machining area. More importantly, no delamination was detected on the cross section of CFRP workpiece which was the main benefit of the multiple-ring laser drilling. Figure 11 shows drilled CFRP morphology (with stepped laser parameter multiple-ring drilling method) examined using scanning electron microscopy (SEM). On the hole edge, there was an obvious de-bounded fibre which was due to the absence of resin. The cross-section formed a recast layer, and no obvious fibres were extruding out of the matrix. However, striation lines were present near the hole exit, which was due to the formation of a cyclic erosion front. The frequency of striation formation was more relevant to the transverse speed and laser power [6].

According to the experimental results from S3 and S5, the stepped laser parameter multiple-ring drilling method greatly reduced the drilling time by varying laser energy input during laser drilling process. In laser drilling of CFRP process, the drilling quality on CFRP workpiece was mainly dominated by the laser and material interaction time and thermal energy input in each laser scan. Therefore, a balance must be maintained between these two variables during drilling, for example, sample S4, which had the least drilling time and greatest laser energy input in each laser scan. However, the drilling quality was the worst due to excessive laser energy input in each laser scan. Meanwhile, S3 showed a good balance between laser drilling time and laser energy input. Thus, the result was considered as the best set among S1-S4. In this research, the change of pulse frequency was achieved by using a function generator. Therefore, it would be crucial 
to synchronize generated pulse frequency with the motion of CNC machine. Otherwise, the protection from the first ring would be hampered if too high a pulse frequency was applied. Manually change of pulse frequency or laser power would not be suggested for stepped laser parameter multiple-ring drilling method. Once the laser system stops emitting the laser, the residual heat left inside the CFRP workpiece starts dissipating. Thus, an additional amount of laser energy would be needed to reheat the material instead of being used for the material removal, which would result in lower drilling efficiency.
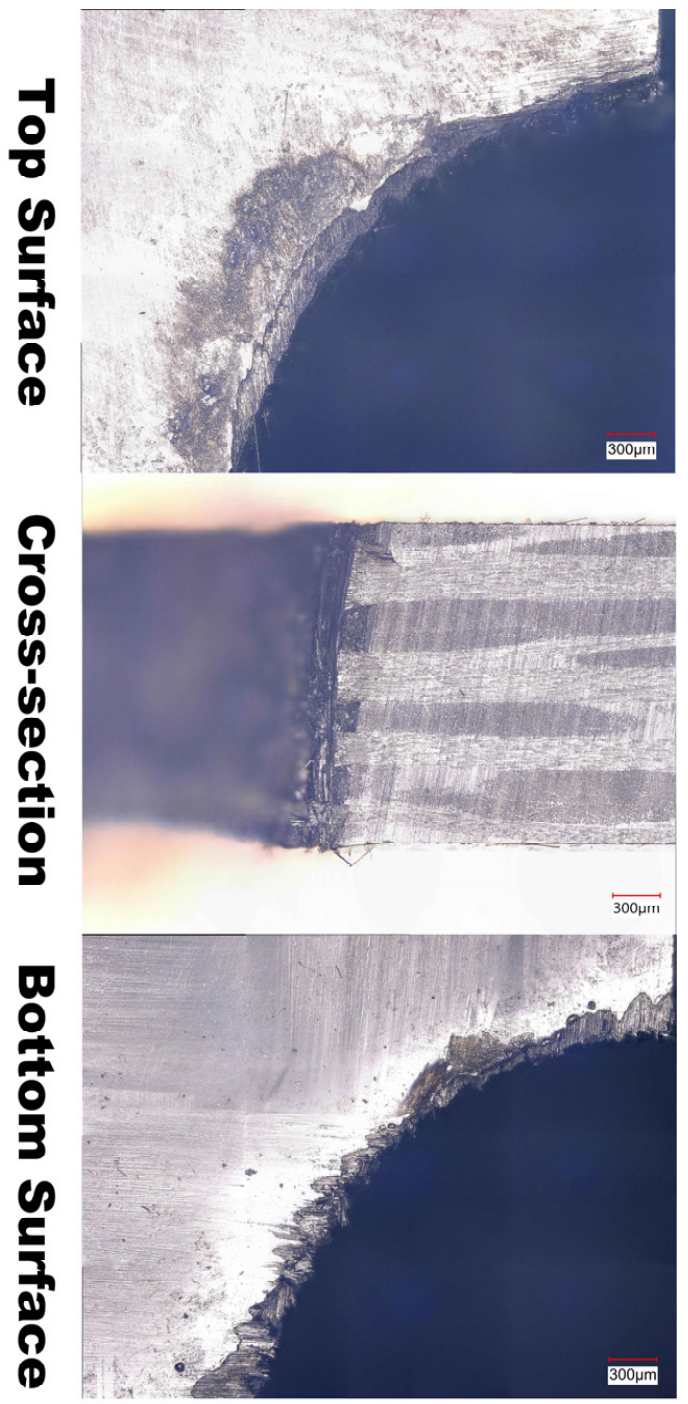

(a)
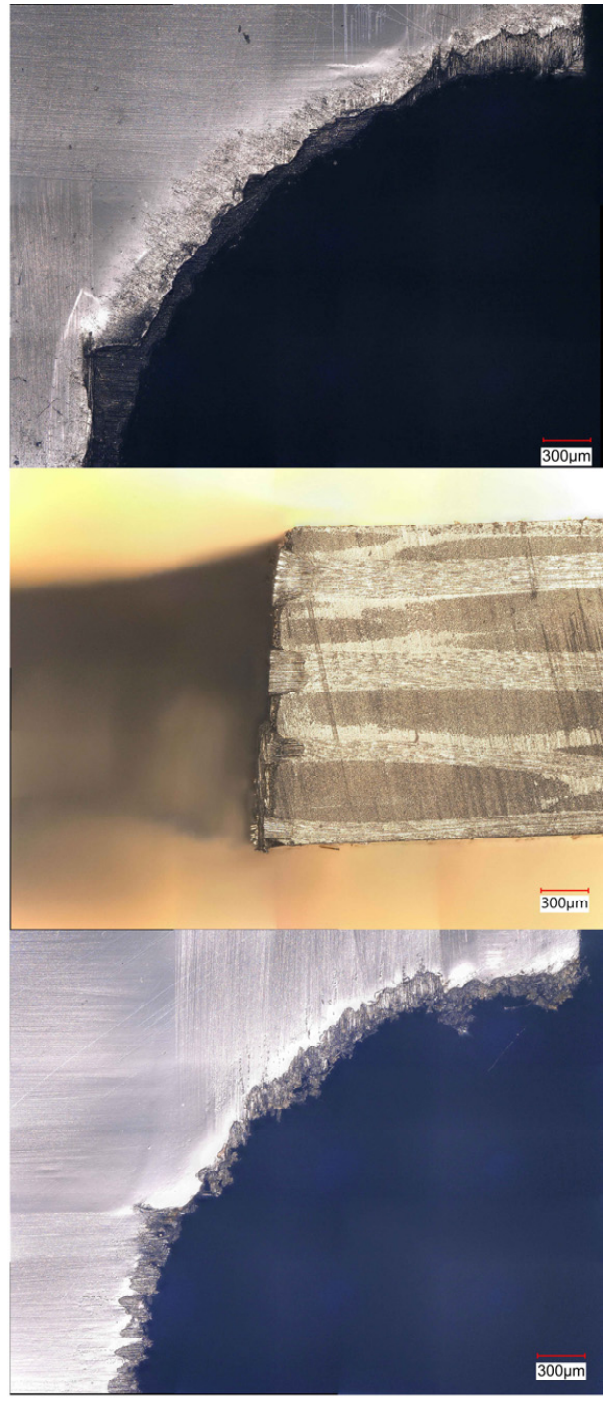

(b)

Figure 10. Optical images of CFRP workpieces drilled via the following different methods: (a) stepped laser parameter multiple-ring drilling method; (b) constant laser parameter multiple-ring drilling method.

\subsection{Evaluation of Energy Consumption and Carbon Footprints}

Laser system energy consumption was measured using a Fluke 434 power/energy analyser, which was based on the ISO 14955-1:2017 standard for data collection method [43]. The energy consumptions include those of laser cell, computer numerical control (CNC) motion system, water chiller, computer control system, and function generator for laser pulse control. According to the result, the stepped laser parameter multiple-ring drilling method led to a significant reduction in drilling time and energy consumption, as shown in Table 6. The drilling time was reduced from $247 \mathrm{~s}$ to $53 \mathrm{~s}$, which was a $78.54 \%$ im- 
provement over that of the constant laser parameter multiple-ring drilling method. The material removal rate in the stepped laser parameter multiple-ring drilling method was $3.58 \times 10^{-7} \mathrm{~kg} / \mathrm{s}$, which was higher than that in the constant laser parameter multiple-ring drilling method $\left(7.67 \times 10^{-8} \mathrm{~kg} / \mathrm{s}\right)$ due to the increased laser energy input in the inner rings. During the laser drilling process, an increase in hatch distance lead to an increased gap width between each ring. Since the carbon fibre was chopped off by the laser beam between two adjacent rings, the thermal conduction through the fibre to the base material was prevented and the material inside the ring could be considered as an isolated area. When the resin was disintegrated, it lost its ability to hold the fibre. Therefore, chopped fibres were ejected from the drilling area by the argon gas once it was de-bounded from the resin. Hence, the increasing hatch distance was able to increase the material removal rate in the inner rings. Figures 12 and 13 show the active power profiles for the stepped laser parameter multiple-ring drilling method and constant laser parameter multiple-ring drilling method. Since the laser power and pulse frequency were increased for the inner rings in the stepped laser parameter multiple-ring drilling method, the laser power profile showed a jagged shape.
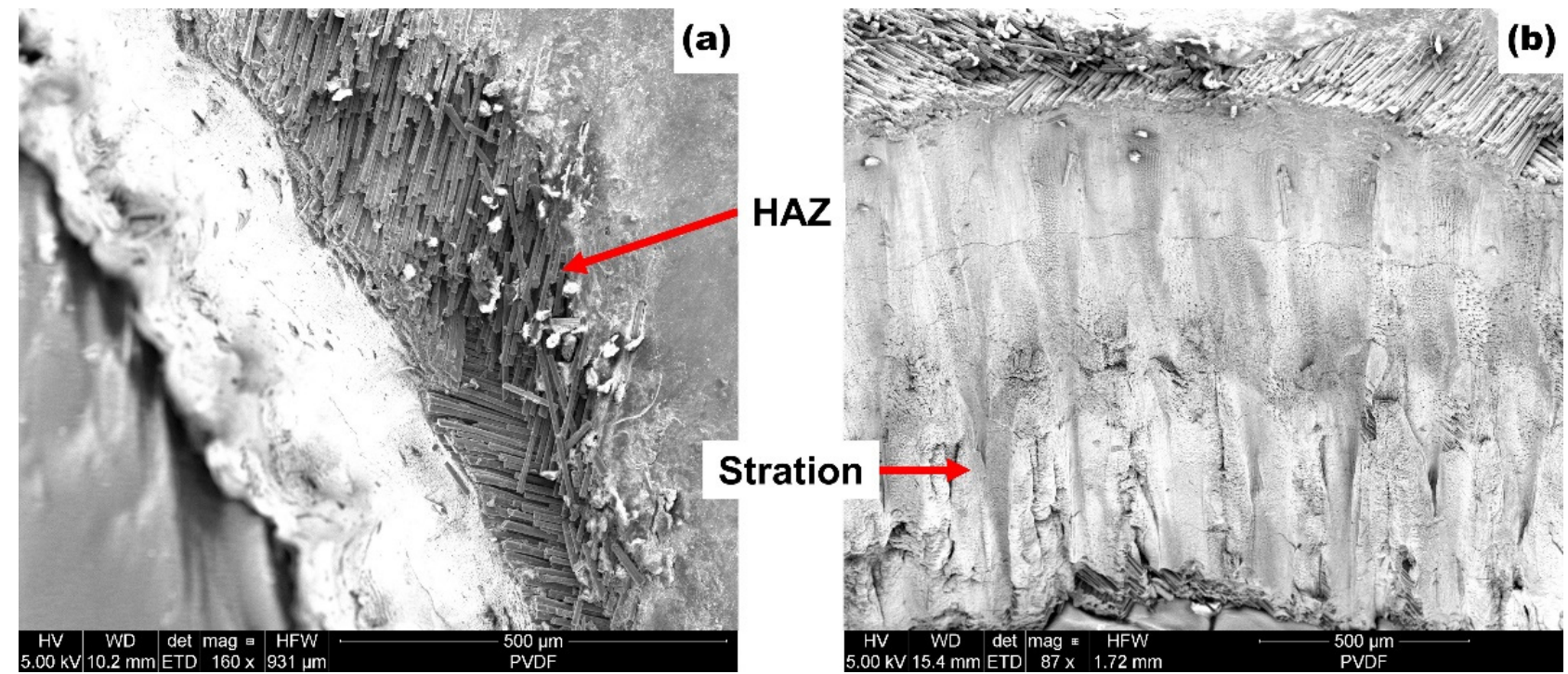

Figure 11. SEM image of drilled CFRP workpiece via stepped laser parameter multiple-ring drilling method: (a) top surface; (b) cross-section.

Table 6. Specific energy consumption and drilling time for each method under the similar drilling quality.

\begin{tabular}{|c|c|c|c|}
\hline & $\begin{array}{l}\text { Stepped Laser Parameter } \\
\text { Multiple Ring Drilling } \\
\text { Method (S3) }\end{array}$ & $\begin{array}{l}\text { Constant Laser Parameter } \\
\text { Multiple Ring Drilling } \\
\text { Method (S5) }\end{array}$ & $\begin{array}{c}\text { Rate of Improvement } \\
\text { between S3 and S5 }\end{array}$ \\
\hline Drilling time (s) & 53.00 & 247.00 & $78.54 \%$ \\
\hline Material removal (mg) & $19.00( \pm 1.70)$ & $18.95( \pm 3.18)$ & - \\
\hline Specific material removal rate $(\mathrm{kg} / \mathrm{s})$ & $3.58 \times 10^{-7}$ & $7.67 \times 10^{-8}$ & $78.58 \%$ \\
\hline Material removal rate $\left(\mathrm{mm}^{3} / \mathrm{s}\right)$ & 0.2439 & 0.0522 & $78.60 \%$ \\
\hline Total energy consumption (J) & $72,547.00$ & $331,223.00$ & $78.10 \%$ \\
\hline $\begin{array}{l}\text { Specific energy consumption for } \\
\text { removing } 1 \mathrm{~kg} C \mathrm{CFRP}(\mathrm{J} / \mathrm{kg})\end{array}$ & $3.82 \times 10^{9}$ & $1.75 \times 10^{10}$ & $78.17 \%$ \\
\hline Carbon emission $\left(\mathrm{gCO}_{2}\right)$ & 5.15 & 23.52 & $78.10 \%$ \\
\hline
\end{tabular}




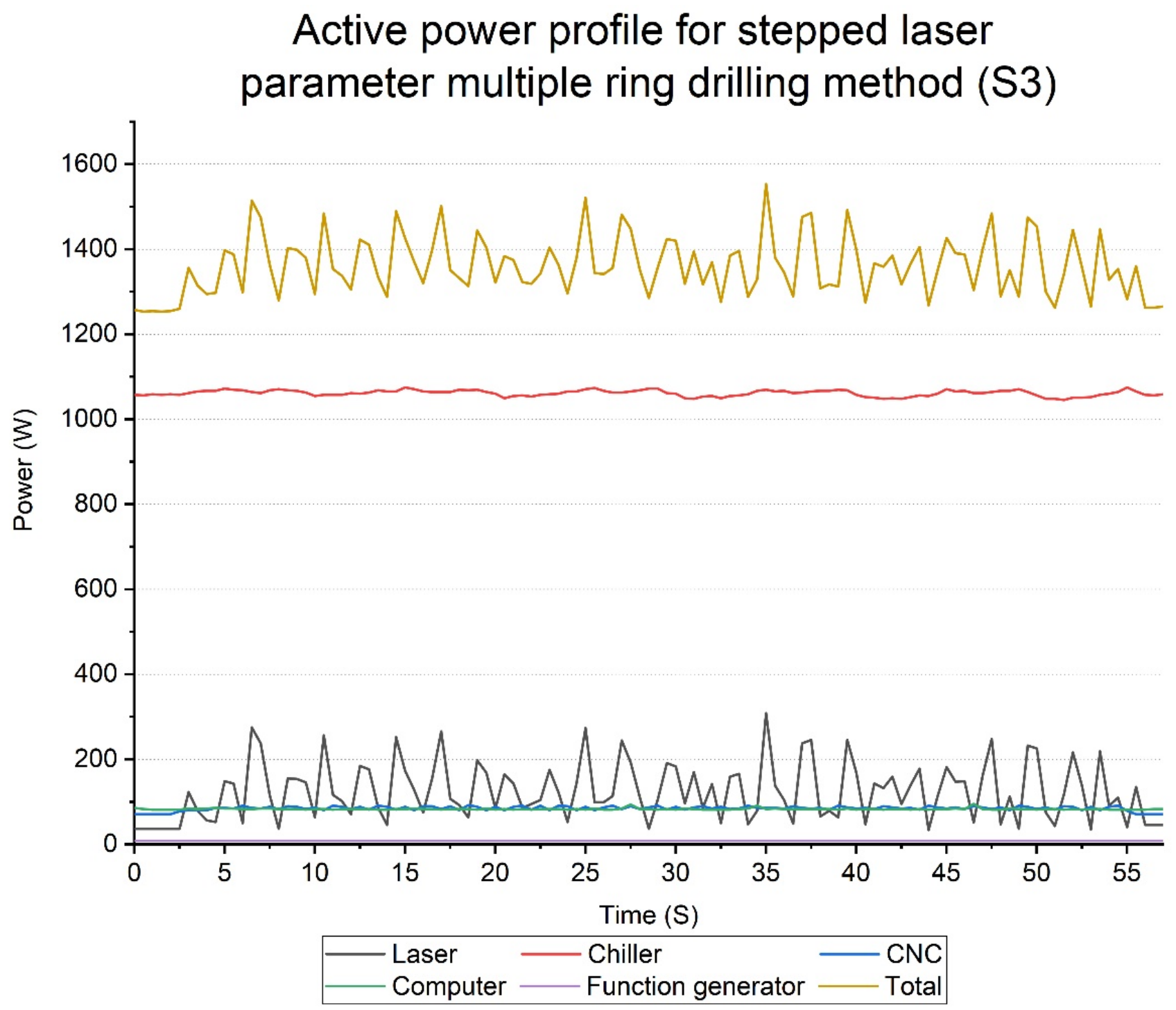

Figure 12. Illustration of Total active power profile and sub-device power profile for Stepped laser parameter multiple-ring drilling method.

As a result of the reduced drilling time in the stepped laser parameter multiplering drilling method, the total energy consumption was also reduced significantly from $331,223 \mathrm{~J}$ for the constant laser parameter multiple-ring drilling method to $72,547 \mathrm{~J}$ for the stepped laser parameter multiple-ring drilling method, as shown in Figure 14. This is a $78.10 \%$ improvement in the total energy consumption. The specific energy consumption to remove $1 \mathrm{~kg}$ of CFRP was $1.75 \times 10^{10} \mathrm{~J} / \mathrm{kg}$ for the constant laser parameter multiplering drilling method and $3.82 \times 10^{9} \mathrm{~J} / \mathrm{kg}$ for the stepped laser parameter multiple-ring drilling method calculated from Equation (2). The electricity carbon factor in the UK is $0.2556 \mathrm{kgCO}_{2} / \mathrm{kWh}$ [36]. Thus, the carbon emissions from the laser drilling process were calculated form Equation (1), which was $23.52 \mathrm{gCO}_{2}$ for constant laser parameter multiplering drilling method and $5.15 \mathrm{gCO}_{2}$ for the stepped laser parameter multiple-ring drilling method. It shows that the stepped laser parameter multiple-ring drilling method had a $78.10 \%$ reduction in carbon emission. 


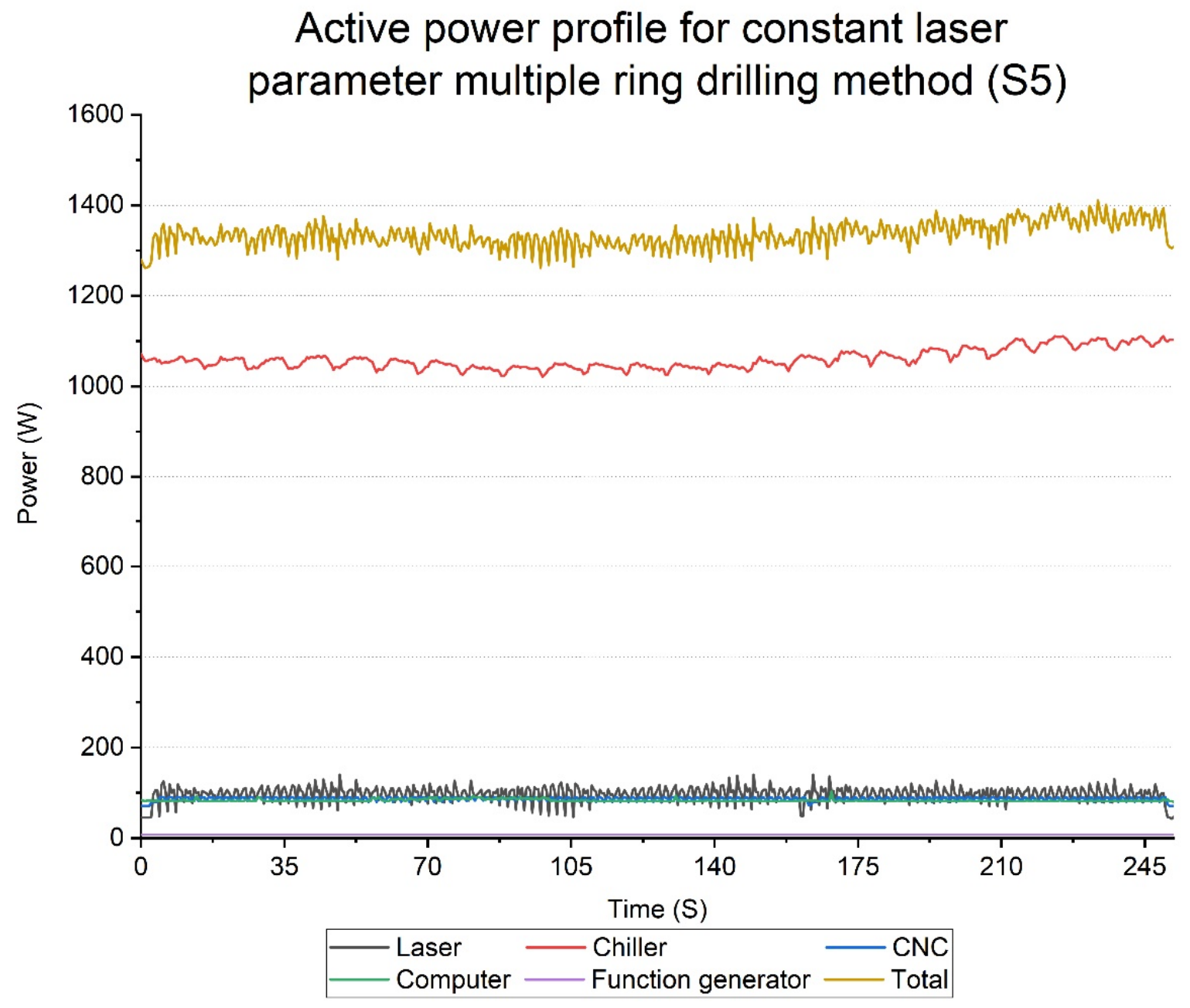

Figure 13. Illustration of total active power profile and sub-device power profile for Constant laser parameter multiple-ring drilling method.

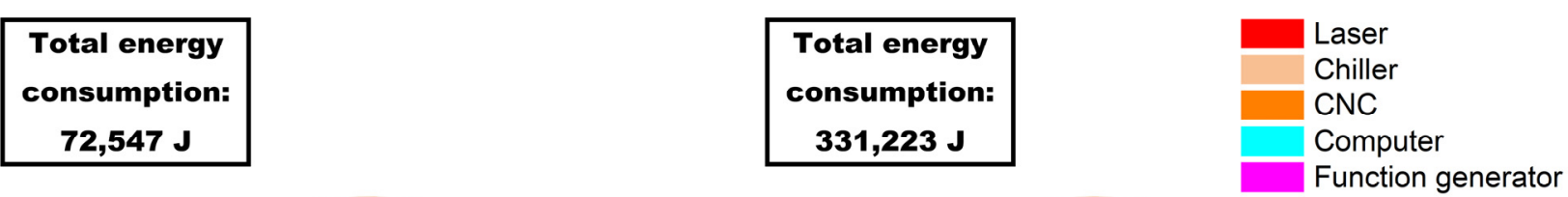

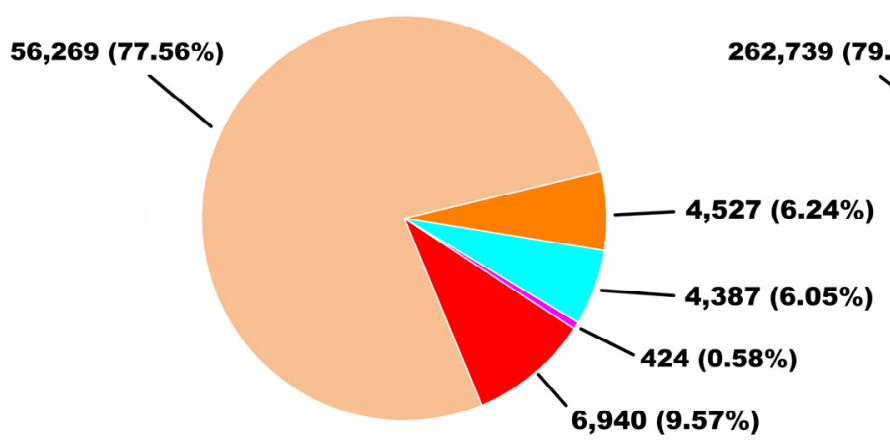

(a)

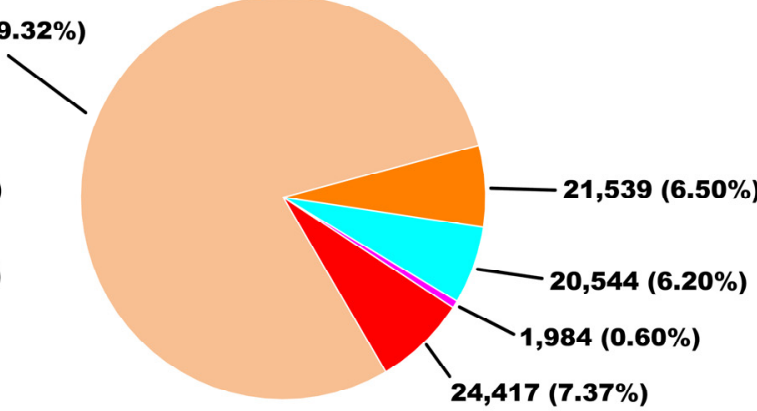

(b)

Figure 14. Energy consumption profile for (a) stepped laser parameter multiple-ring drilling method; (b) constant laser parameter multiple-ring drilling method. 


\subsection{Evaluation of Bearing Strength}

Mechanical fastening is a commonly accepted method to join CFRP workpieces with other materials. The contact force acting between fastener and CFRP material may cause bearing failure. Figure 15 shows an example load versus displacement curve for the CFRP workpiece being drilled via different methods. As the load was applied to the pin, the load and displacement curve was progressed in a linear trend until a sudden drop occurred in the load. The average maximum load was $2.76 \mathrm{kN}( \pm 0.10)$ at a $0.83 \mathrm{~mm}$ $( \pm 0.15)$ displacement for the sample drilled via the stepped laser parameter multiplering drilling method. In the case of the constant laser parameter multiple-ring drilling method, the average maximum load was $2.97 \mathrm{kN}( \pm 0.08)$ at a displacement of $0.72 \mathrm{~mm}$ $( \pm 0.15)$. According to the experimental data, a slight difference $(7 \%)$ was detected in average maximum load to initiate bearing failure between the two methods. The average maximum load for mechanical drilling was $3.56 \mathrm{kN}(( \pm 0.19)$ at a displacement of $0.60 \mathrm{~mm}$ $(( \pm 0.07)$. Moreover, there was no difference in failure mode for the hole being drilled via the stepped laser parameter multiple-ring drilling method, constant laser parameter multiple-ring drilling method, and traditional mechanical drilling process.

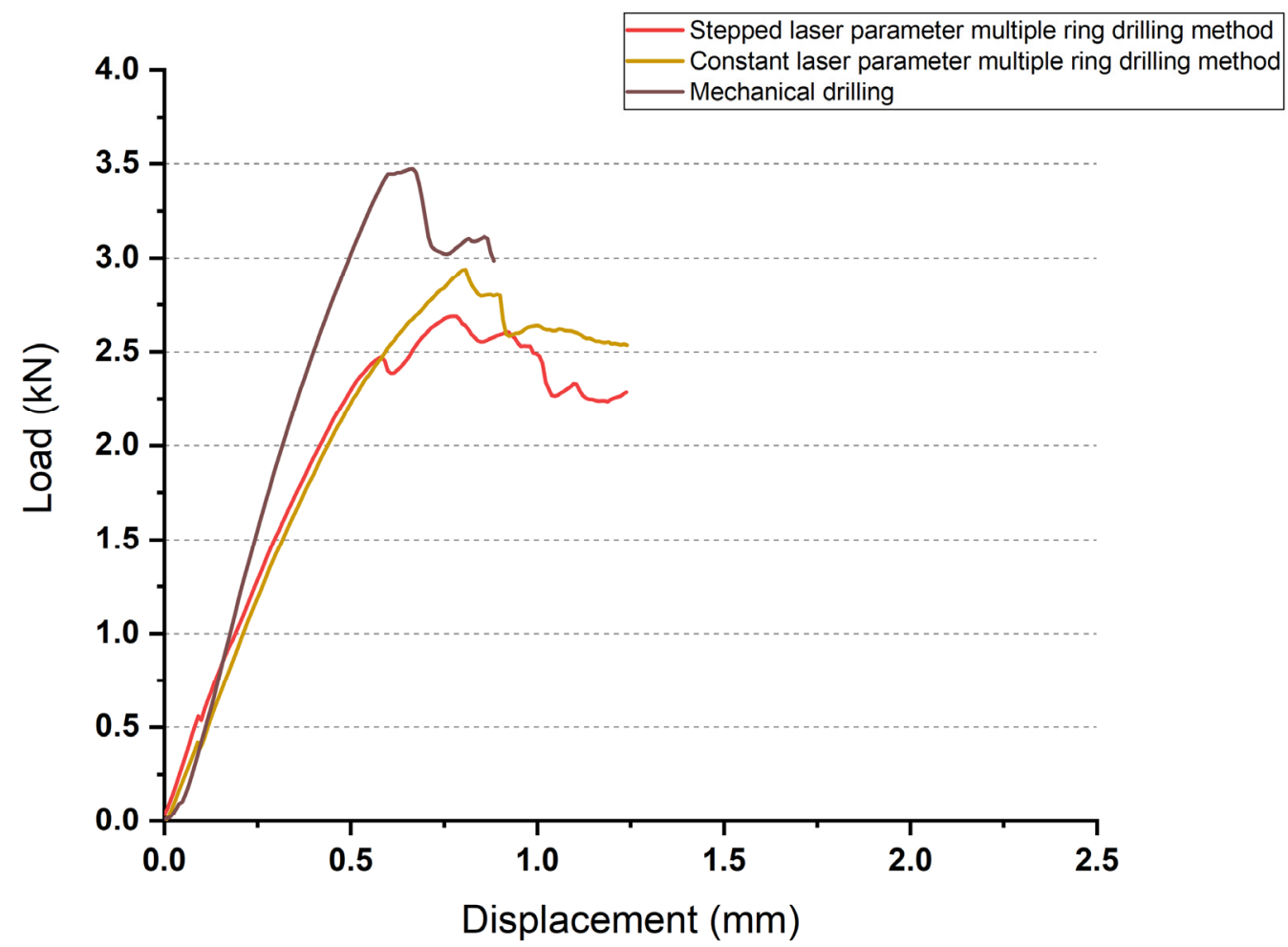

Figure 15. Evaluation trends of load versus displacement.

\subsection{Mechanical Finishing}

The mechanical drill bit was engaged reversely from the laser drilling hole exit side. No supporting material or special designed drill bit were used in the dry drilling of the CFRP workpiece. After the laser drilling, the average HAZ left on bottom surface was $161.70 \mu \mathrm{m}( \pm 1.79)$ and $316.25 \mu \mathrm{m}( \pm 67.99)$ on top surface. Figure 16 shows the comparison of the hole quality between the laser drilled pilot hole and mechanical finished hole. On the cross-sectional view, the HAZ and taper angle were removed by the mechanical finishing process. More importantly, no delamination was detected at the hole exit. This result was achieved with the assistance of mechanical finishing with reversed feed drilling strategy. No supporting material and special designed drill bit were used in this dry mechanical finishing process. With the assistance of this novel drilling strategy, a good balance between drilling quality and drilling cost was able to be achieved. 


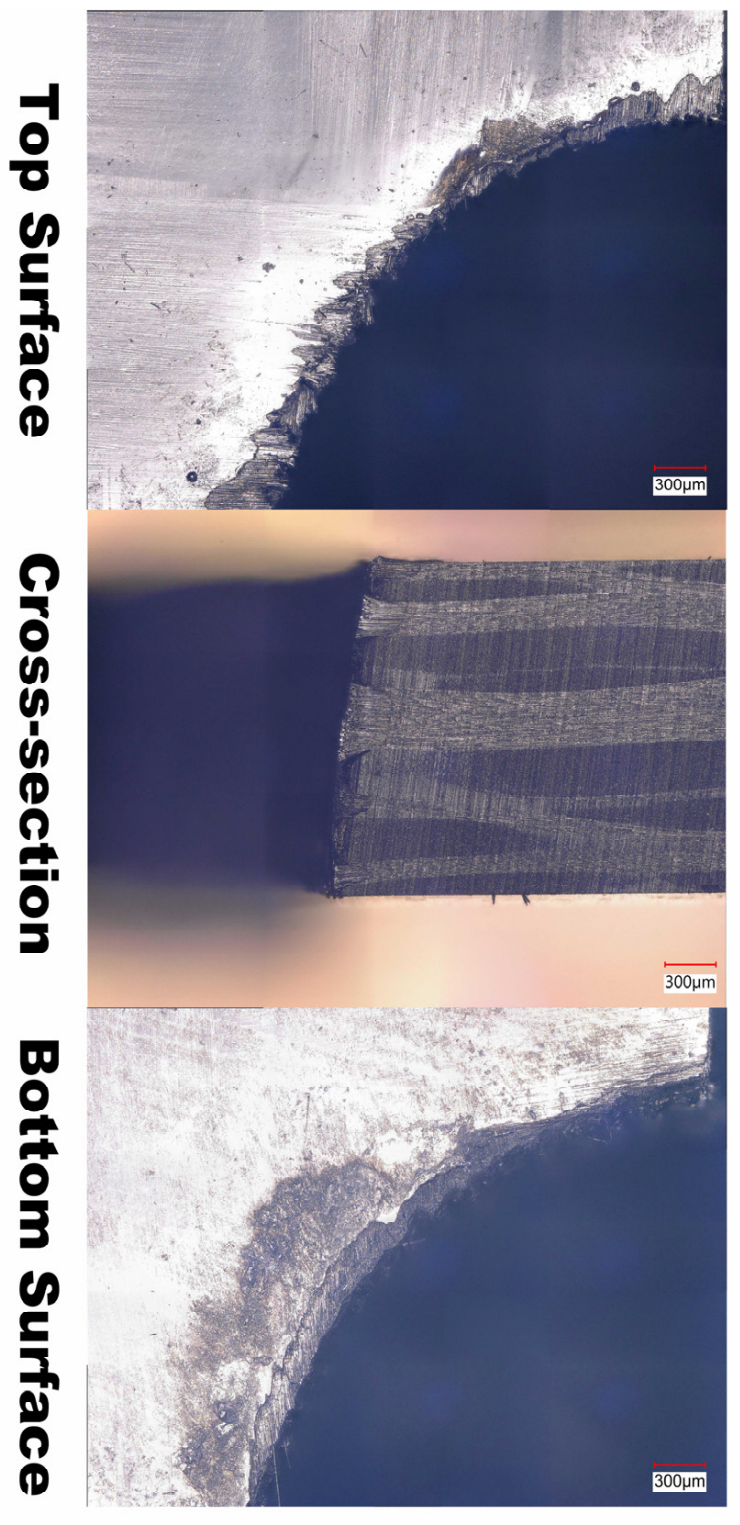

(a)
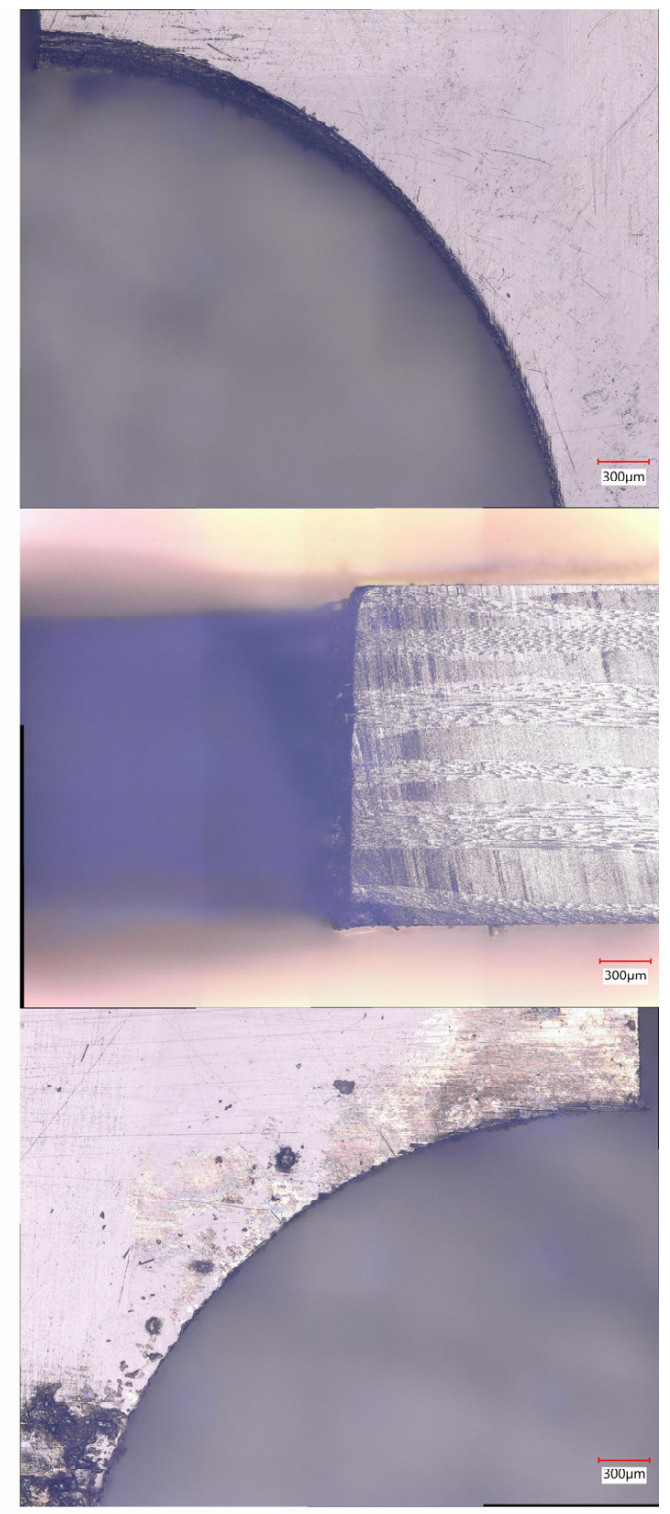

(b)

Figure 16. Comparison of hole quality: (a) laser drilled pilot hole; (b) mechanical finished hole.

\section{Discussion}

This research has shown that by introducing stepped parameter parallel drilling laser drilling method, significant benefit can be gained in terms of drilling efficiency and energy consumption reduction, without sacrificing the drilling quality compared with the previously reported parallel ring laser drilling with constant drilling parameters. The temperature profiles in laser parallel ring processing of CFRP has been previously studied, e.g., Li et al. [33]. The key findings from the previous temperature profile study are the rapid damage and disintegration of the resin by the high temperature of the highly conducting carbon fibre and direct laser irradiation. The parallel ring drilling can more effectively prevent heat from the inner drilling rings from expanding through the cut channels of the outer ring to the parent material, and carbon fibres can be removed more effectively by multiple rings by chopping them into short fibres rather than vaporizing them all. The key difference is that, in the present study using a stepped parameter parallel ring approach, the outer ring can be produced using a lower energy input to limit the heat affected zone, while preventing the heat from inner rings from reaching the parent material. A higher 
energy input was used for the inner rings to remove the material more rapidly. It should be noted that in this laser drilling process, the hole drilling was realized by only cutting out a central disk, rather than vaporizing the entire material in the hole centre, thus the energy consumption can be significantly reduced.

In conventional mechanical drilling, although much less energy is used during the drilling process, hole delamination damage and tool wear would occur, which is dependent on the type of drilling tools and material size and applications. Thus, the analysis of energy consumption for the replacement of drilling tools (depending on how the tools are made, what tool and coating materials are used) and loss of damaged product (say, a CFRP panel with $\mathrm{x} \%$ of failed holes) in specific applications would be much more complex, thus beyond the scope of the current study. More detailed bench marking against conventional drilling will be studied in the near future using "from cradle to grave" full life cycle analysis.

The key problem of mechanical drilling is the fibre delamination in the hole exit, as shown in Figure 17, drilled using the same drill bit as shown in Table 5, in addition to the significant tool wear. A good drilling tool can typically drill 20-30 holes in CFRP, depending on the material thickness. Replacement of these tools would result in significant energy consumption and cost.

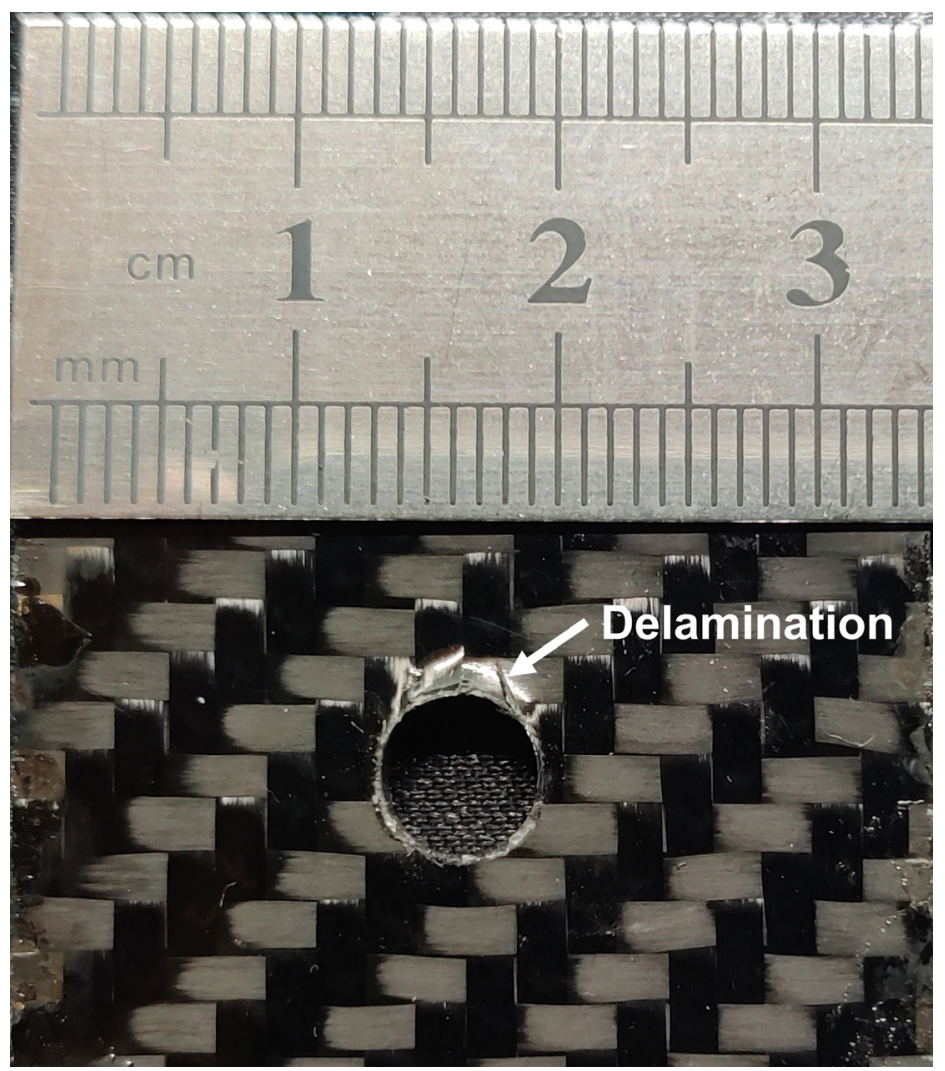

Figure 17. Mechanical drilling process induced delamination at the hole exit.

The current research is the first step in understanding of energy efficiency in laser drilling holes in CFRP with a workpiece thickness of $2 \mathrm{~mm}$. In practical applications, such as the manufacture of modern aircraft structures in Boeing 787 and Airbus A350, a significant proportion (50-60\% by weight) of aircraft panels are made of CFRP of sheets of 5-75 mm in thickness, and many thousands of fastening holes are needed in these CFRP panels. Tool wear and quality control are critical considerations. In order to reduce damage to the CFRP, very high-cost special tools are needed and tool wear would lead to significant cost and overall energy consumptions not just to the aircraft manufacturers but also to the supply chains. 
A rapid laser pre-scribing process, followed by standard mechanical drilling, is designed to chop off the continuous fibre at the hole exit periphery. Then, mechanical drilling is carried out from the opposite side to avoid hole exit fibre delamination. This is illustrated in Figure 18 together with the effect of drilling to demonstrate that fibre delamination can be avoided without a backing plate in mechanical drilling. The mechanical drilling took about $2 \mathrm{~s}$ and the laser pre-scribing took about $2 \mathrm{~s}$. If both are carried out simultaneously, then there would be no time delay to the mechanical drilling process. This, however, does not solve the problem of tool wear. A more detailed study of this novel process will be presented elsewhere.

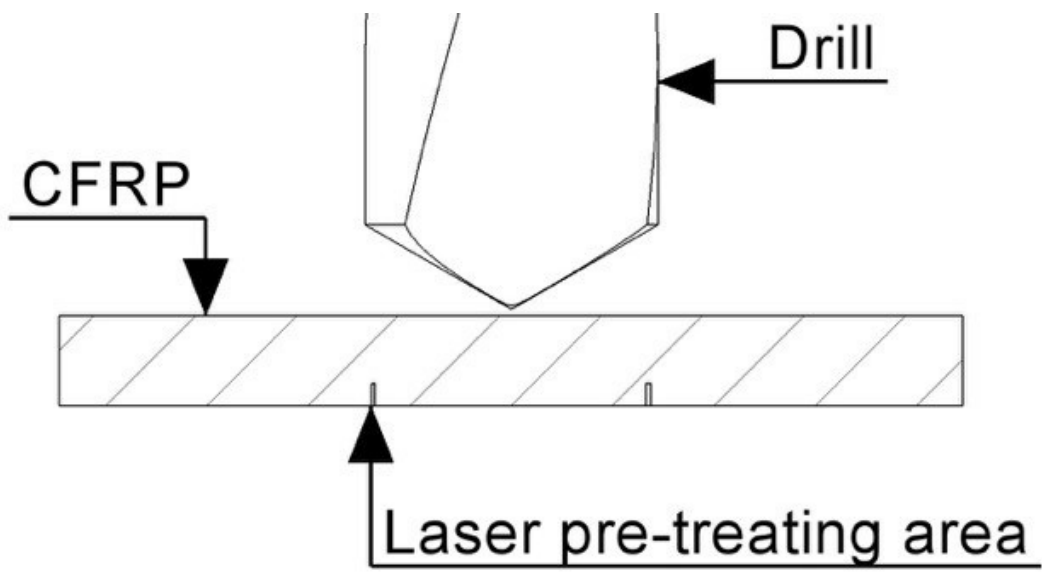

(a)

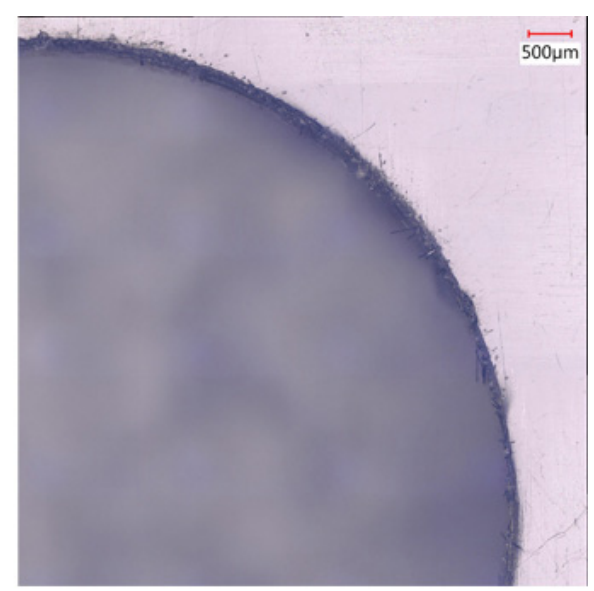

(b)

Figure 18. (a) Schematic diagram of combined laser pretreatment and mechanical hole drilling process; (b) Hole exit showing no fibre delamination.

Laser drilling alone, while taking longer than mechanical drilling with the present set up, eliminates the problem of tool wear and fibre delamination at the hole exit associated with mechanical drilling. With the availability of high-power picosecond and nanosecond lasers, both drilling time and quality can be expected to be further improved.

\section{Conclusions}

This research demonstrates a new CFRP hole-drilling method-the stepped laser parameter multiple-ring drilling method. The main findings in this research are summarised below.

- The stepped laser parameter multiple-ring drilling strategy leads to a $78.54 \% \mathrm{im}-$ provement in drilling time, i.e., over 300\% increase in productivity, while reducing energy consumption by $78.10 \%$ compared with that of the constant laser parameter multiple-ring drilling method.

- The carbon emission from the stepped laser parameter multiple-ring drilling method is reduced to $5.15 \mathrm{gCO}_{2}$, less than a quarter of that in the constant laser parameter multiple-ring drilling method of $23.52 \mathrm{gCO}_{2}$.

- The specific energy consumption to remove $1 \mathrm{mg}$ of CFRP in a process period by the stepped laser parameter multiple-ring drilling method and the constant laser parameter multiple-ring drilling method is $3.82 \times 10^{9} \mathrm{~J} / \mathrm{kg}$ and $1.75 \times 10^{10} \mathrm{~J} / \mathrm{kg}$, respectively.

- The key reason for this significant reduction in drilling time and energy requirement is the increase in energy input for the inner rings for the more rapid removal of the material, while the lower energy input generated outer ring provided a shield trench to stop the heat transition into the parent material.

- Mechanical bearing response test shows that a laser drilled hole via stepped laser parameter multiple-ring drilling method has similar maximum failure load and load- 
displacement trend as that of samples drilled via constant laser parameter multiplering drilling method, but lower than that drilled mechanically.

- The mechanical finishing process shows that a reversed-feed drilling strategy was able to suppress delamination at the hole exit without using supporting material and a specially designed drilling tool.

- With this new method, one can simultaneously minimise the drilling time and reduce environmental impact without sacrificing much on the drilling quality.

- A new combined rapid laser pre-scribing followed by mechanical hole drilling has been briefly demonstrated to avoid fibre delamination at the hole exit.

- The current study shows that laser drilling time (53 s) is still considerably longer than that for mechanical drilling (about $2 \mathrm{~s}$ ), although the laser drilling eliminates the tool wear and fibre delamination at the hole exit. With the availability of high-power picosecond and femtosecond lasers, both drilling time and drilling quality can be further improved.

Further study could be undertaken to benchmark against conventional mechanical drilling processes using "cradle to grave" full life cycling energy consumption analysis considering the tool wear loss in mechanical drilling. More in-depth theoretical modelling of the temperature profiles and material flow characteristic using computational fluid dynamics and finite element modelling will be carried out to understand the process dynamics and material behaviour. More industrial application-relevant studies of drilling thicker CFRP materials will be carried out.

Author Contributions: Project supervision: L.L. and P.M.; methodology: M.Z., C.W., W.G., Z.Z. and J.O.; writing original draft, M.Z.; writing—review and editing: L.L., P.M. and M.Z., All authors have read and agreed to the published version of the manuscript.

Funding: EPSRC grant reference EP/S018190/1, UK.

Institutional Review Board Statement: Not applicable.

Informed Consent Statement: Not applicable.

Data Availability Statement: The University of Manchester library PhD thesis archive.

Acknowledgments: The authors are grateful to the MACE mechanical workshop for the assistance in the shearing test and mechanical finishing. The authors acknowledge the partial support of the research by Engineering and Physical Sciences Research Council (EPSRC) under grant EP/S018190/1.

Conflicts of Interest: The authors declare no conflict of interest.

\section{References}

1. Geng, D.; Liu, Y.; Shao, Z.; Lu, Z.; Cai, J.; Li, X.; Jiang, X.; Zhang, D. Delamination formation, evaluation and suppression during drilling of composite laminates: A review. Compos. Struct. 2019, 216, 168-186. [CrossRef]

2. Staehr, R.; Bluemel, S.; Jaeschke, P.; Suttmann, O.; Overmeyer, L. Laser cutting of composites-Two approaches toward an industrial establishment. J. Laser Appl. 2016, 28, 022203. [CrossRef]

3. Ebewele, R.O. Polymer Science and Technology; CRC Press: Boca Raton, FL, USA, 2000; ISBN 9781420057805.

4. Pastuszak, P.D.; Muc, A. Application of composite materials in modern constructions. Key Eng. Mater. 2013, 542, 119-129. [CrossRef]

5. Chung, D.D.L. Carbon Fiber Composites; Elsevier: Amsterdam, The Netherlands, 2012; ISBN 0750691697.

6. Sheikh-Ahmad, J.Y. Machining of Polymer Composites; Springer: New York, NY, USA, 2009; ISBN 9780387355399.

7. Salama, A.; Li, L.; Mativenga, P.; Whitehead, D. TEA CO $\mathrm{CO}_{2}$ laser machining of CFRP composite. Appl. Phys. A Mater. Sci. Process. 2016, 122, 497. [CrossRef]

8. John, K.M.; Kumaran, S.T.; Kurniawan, R.; Moon Park, K.; Byeon, J.H. Review on the methodologies adopted to minimize the material damages in drilling of carbon fiber reinforced plastic composites. J. Reinf. Plast. Compos. 2019, 38, 351-368. [CrossRef]

9. Kalla, D.; Sheikh-Ahmad, J.; Twomey, J. Prediction of cutting forces in helical end milling fiber reinforced polymers. Int. J. Mach. Tools Manuf. 2010, 50, 882-891. [CrossRef]

10. Martin, H. Aerospace in Focus: Drilling and Milling CFRP Composites. 2018. Available online: https://www.mscdirect.com/ betterMRO/metalworking/aerospace-focus-drilling-and-milling-cfrp-composites (accessed on 23 December 2021).

11. Khan, Z. A Study of the Drilling of Advanced Carbon Fibre Composites. Ph.D. Thesis, University of Salford, Salford, UK, 1991. 
12. Hocheng, H.; Tsao, C.C. The path towards delamination-free drilling of composite materials. J. Mater. Process. Technol. 2005, 167, 251-264. [CrossRef]

13. Jia, Z.; Fu, R.; Niu, B.; Qian, B.; Bai, Y.; Wang, F. Novel drill structure for damage reduction in drilling CFRP composites. Int. J. Mach. Tools Manuf. 2016, 110, 55-65. [CrossRef]

14. Tsao, C.C.; Hocheng, H.; Chen, Y.C. Delamination reduction in drilling composite materials by active backup force. CIRP Ann.-Manuf. Technol. 2012, 61, 91-94. [CrossRef]

15. Yu, Z.; Li, C.; Kurniawan, R.; Park, K.M.; Ko, T.J. Drill bit with a helical groove edge for clean drilling of carbon fiber-reinforced plastic. J. Mater. Process. Technol. 2019, 274, 116291. [CrossRef]

16. Su, F.; Wang, Z.; Yuan, J.; Cheng, Y. Study of thrust forces and delamination in drilling carbon-reinforced plastics (CFRPs) using a tapered drill-reamer. Int. J. Adv. Manuf. Technol. 2015, 80, 1457-1469. [CrossRef]

17. Feito, N.; Díaz-Álvarez, J.; López-Puente, J.; Miguelez, M.H. Experimental and numerical analysis of step drill bit performance when drilling woven CFRPs. Compos. Struct. 2018, 184, 1147-1155. [CrossRef]

18. Li, W.; Zhang, G.; Huang, Y.; Rong, Y. Drilling of CFRP plates with adjustable pulse duration fiber laser. Mater. Manuf. Process. 2021, 36, 1256-1263. [CrossRef]

19. El-Hofy, M.; Helmy, M.O.; Escobar-Palafox, G.; Kerrigan, K.; Scaife, R.; El-Hofy, H. Abrasive Water Jet Machining of Multidirectional CFRP Laminates. Procedia Cirp 2018, 68, 535-540. [CrossRef]

20. Rao, S.; Sethi, A.; Das, A.K.; Mandal, N.; Kiran, P.; Ghosh, R.; Dixit, A.R.; Mandal, A. Fiber laser cutting of CFRP composites and process optimization through response surface methodology. Mater. Manuf. Process. 2017, 32, 1612-1621. [CrossRef]

21. Islam, M.M.; Li, C.P.; Won, S.J.; Ko, T.J. A deburring strategy in drilled hole of CFRP composites using EDM process. J. Alloys Compd. 2017, 703, 477-485. [CrossRef]

22. El-Hofy, M.H.; El-Hofy, H. Laser beam machining of carbon fiber reinforced composites: A review. Int. J. Adv. Manuf. Technol. 2019, 101, 2965-2975. [CrossRef]

23. Li, Z.L.; Zheng, H.Y.; Lim, G.C.; Chu, P.L.; Li, L. Study on UV laser machining quality of carbon fibre reinforced composites. Compos. Part A Appl. Sci. Manuf. 2010, 41, 1403-1408. [CrossRef]

24. Salama, A.; Yan, Y.; Li, L.; Mativenga, P.; Whitehead, D.; Sabli, A. Understanding the self-limiting effect in picosecond laser single and multiple parallel pass drilling/machining of CFRP composite and mild steel. Mater. Des. 2016, 107, 461-469. [CrossRef]

25. Salama, A.; Li, L.; Mativenga, P.; Sabli, A. High-power picosecond laser drilling/machining of carbon fibre-reinforced polymer (CFRP) composites. Appl. Phys. A Mater. Sci. Process. 2016, 122, 73. [CrossRef]

26. Negarestani, R.; Sundar, M.; Sheikh, M.A.; Mativenga, P.; Li, L.; Li, Z.L.; Chu, P.L.; Khin, C.C.; Zheng, H.Y.; Lim, G.C. Numerical simulation of laser machining of carbon-fibre-reinforced composites. Proc. Inst. Mech. Eng. Part B J. Eng. Manuf. 2010, 224, 1017-1027. [CrossRef]

27. Negarestani, R.; Li, L.; Sezer, H.K.; Whitehead, D.; Methven, J. Nano-second pulsed DPSS Nd: YAG laser cutting of CFRP composites with mixed reactive and inert gases. Int. J. Adv. Manuf. Technol. 2010, 49, 553-566. [CrossRef]

28. Tagliaferri, V.; Visconti, I.C.; Di Ilio, A. Machining of fibre reinforced materials with laser beam: Cut quality evaluation. In Proceedings of the Sixth International Conference on Composite Material, London, UK, 20-24 July 1987.

29. Tagliaferri, V. Laser cutting of reinforced materials. In Handbook of Ceramics and Composites; Marcel Dekker: New York, NY, USA, 1990; pp. 451-467.

30. Leone, C.; Genna, S. Heat affected zone extension in pulsed Nd:YAG laser cutting of CFRP. Compos. Part B Eng. 2018, 140, 174-182. [CrossRef]

31. Goeke, A.; Emmelmann, C. Influence of laser cutting parameters on CFRP part quality. Phys. Procedia 2010, 5, 253-258. [CrossRef]

32. Lawrence, J.; Pou, J.; Low, D.K.Y.; Toyserkani, E. Advances in Laser Materials Processing: Technology, Research and Application; Woodhead Publishing: Sawston, UK, 2010; ISBN 9781845694746.

33. Li, M.; Li, S.; Yang, X.; Zhang, Y.; Liang, Z. Fiber laser cutting of CFRP laminates with single- and multi-pass strategy: A feasibility study. Opt. Laser Technol. 2018, 107, 443-453. [CrossRef]

34. Tamrin, K.F.; Sheikh, N.A.; Sapuan, S.M. Laser drilling of composite material: A review. In Hole-Making and Drilling Technology for Composites; Woodhead Publishing: Sawston, UK, 2019.

35. Song, Y.S.; Youn, J.R.; Gutowski, T.G. Life cycle energy analysis of fiber-reinforced composites. Compos. Part A Appl. Sci. Manuf. 2009, 40, 1257-1265. [CrossRef]

36. Ouyang, J.; Mativenga, P.T.; Liu, Z.; Li, L. Energy consumption and process characteristics of picosecond laser de-coating of cutting tools. J. Clean. Prod. 2021, 290, 125815. [CrossRef]

37. Double-Sided Carbon Fibre Sheet; $0.25 \mathrm{~mm}, 0.5 \mathrm{~mm}, 1 \mathrm{~mm}, 2 \mathrm{~mm}, 3 \mathrm{~mm}$-Easy Composites. Available online: https://www. easycomposites.co.uk/double-sided-high-strength-carbon-fibre-sheet (accessed on 2 September 2021).

38. Jeswiet, J.; Kara, S. Carbon emissions and CES ${ }^{\mathrm{TM}}$ in manufacturing. CIRP Ann.-Manuf. Technol. 2008, 57, 17-20. [CrossRef]

39. American Society for the Testing and Materials. ASTM Standard Test Method for Open-Hole Compressive Strength of Polymer Matrix Composite Laminates 1. ASTM Compass 2018, 15.03, 1-31. [CrossRef]

40. Geier, N.; Davim, J.P.; Szalay, T. Advanced cutting tools and technologies for drilling carbon fibre reinforced polymer (CFRP) composites: A review. Compos. Part A Appl. Sci. Manuf. 2019, 125, 105552. [CrossRef]

41. $5 \mathrm{~mm}$ Economy Carbide Stub Drill-D5405 (YG-1) ICutwel-Carbide Drill Supplier Cutwel Ltd. Available online: https: //www.cutwel.co.uk/6-5mm-economy-uncoated-carbide-stub-drill-d5405-yg-1-d5405065 (accessed on 5 November 2021). 
42. 6 mm Economy Carbide Stub Drill—D5405 (YG-1) |Cutwel—Carbide Drill Supplier Cutwel Ltd. Available online: https: //www.cutwel.co.uk/6mm-economy-uncoated-carbide-stub-drill-d5405-yg-1-d5405060 (accessed on 5 November 2021).

43. Fysikopoulos, A.; Stavropoulos, P.; Salonitis, K.; Chryssolouris, G. Energy efficiency assessment of laser drilling process. Phys. Procedia 2012, 39, 776-783. 